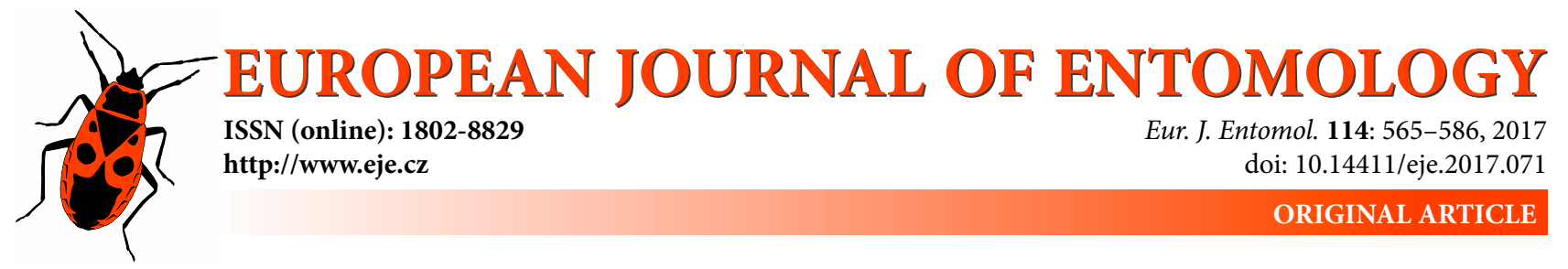

\title{
Detailed morphological descriptions of the immature stages of the ant parasite Microdon mutabilis (Diptera: Syrphidae: Microdontinae) and a discussion of its functional morphology, behaviour and host specificity
}

\author{
Giulia SCARPARO ${ }^{1,3}$, Pierfilippo CERRETTI², Maurizio MEI² and Andrea DI GIULIO ${ }^{1,3, *}$ \\ ${ }^{1}$ Department of Science, University of Roma Tre, Viale Guglielmo Marconi 446, 00146 Rome, Italy; \\ e-mails: giulia.scarparo@uniroma3.it, andrea.digiulio@uniroma3.it \\ 2 Department of Biology and Biotechnology "Charles Darwin”, University of Rome "Sapienza”, Piazzale Valerio Massimo 6 , \\ 00162 Rome, Italy; e-mails: pierfilippo.cerretti@uniroma1.it, maurizio.mei@uniroma1.it \\ ${ }^{3}$ Laboratorio Interdipartimentale di Microscopia Elettronica (L.I.M.E), University of Roma Tre
}

Key words. Diptera, Syrphidae, Microdon mutabilis, development, fly-ant interactions, Formica cunicularia, immature stages, larval behaviour, myrmecophily, scanning electron microscopy

\begin{abstract}
The myrmecophilous immature stages of hover flies of the genus Microdon Meigen, 1803 (Diptera, Syrphidae) are still poorly known and only about 15 species were previously incompletely described and/or illustrated using light microscopy based on occasional findings mainly of pupae and third instar larvae. The exceptional finding of a large number of second and third instar larvae and pupae (159 specimens) of Microdon mutabilis (Linnaeus, 1758) inside the nest of a new host species, Formica cunicularia Latreille,1798, enabled us to rear them and obtain a great number of eggs and first instar larvae. We filmed and described the feeding behaviour and locomotion of these highly derived slug-like larvae. Combining light, fluorescence and scanning electron (SEM) microscopy, we describe in detail and illustrate the external features of all the immature stages of M. mutabilis (eggs, larvae and pupae). Covering the entire chorion of the egg is a peculiar microsculpture composed of volcano-like processes. The three larval instars strongly differ from each other, especially at the level of the shape of the body, the posterior spiracular tubercle and the cephaloskeleton. SEM microscopy was used to describe in detail the microsculpture, sensorial structures, spiracles and cephalic appendages of larvae and pupae. Fluorescence microscopy was used to reveal the exceptional presence of resilin in the external layer of the posterior spiracular tubercle in first instar larvae. The possible functional significance of these structures is discussed.
\end{abstract}

\section{INTRODUCTION}

A plethora of soil dwelling arthropods have evolved complex associations with ants, and this has happened several times independently in ants since they radiated in the Eocene (Parker \& Grimaldi, 2014). These organisms, known as "myrmecophiles", belong to all the major extant lineages of arthropods like arachnids, mites, myriapods, crustaceans and, most importantly in terms of the number of species involved, hexapods (Thomas et al., 2005; Parker \& Grimaldi, 2014; Lachaud et al., 2016). Interactions between ants and their myrmecophiles range from various degrees of mutualism, commensalism, to predation, parasitoidism or parasitism (Hölldobler \& Wilson, 1990; Ivens et al., 2016).

The bulk of myrmecophilous diversity is however restricted to a handful of endopterygote taxa, chiefly lepidopterans, hymenopterans, coleopterans and dipterans (Höll- dobler \& Wilson, 1990). More than 20 families of flies have established, as adults and/or larvae, a great diversity of associations with ants, by behaving as scavengers, kleptoparasites, predators and parasitoids (Hölldobler \& Wilson, 1990). The dipteran family that counts for the highest number of taxa associated with ants is probably the Phoridae, commonly known as ant-decapitating flies (Hölldobler \& Wilson, 1990; Lachaud \& Pérez-Lachaud, 2015; Brown et al., 2017; Pérez-Lachaud et al., 2017). Other examples of fly/ant interactions occur also in the families Milichiidae, Cecidomyiidae, Culicidae and Psychodidae (Wheeler, 1928; Kistner, 1982; Hölldobler \& Wilson, 1990; Pereira et al., 2015), while isolated cases of myrmecophilous species are reported for Bombylidae, Ceratopogonidae, Chironomidae, Sciaridae and Tachinidae (Gösswald, 1950; Hölldobler \& Wilson, 1990; Evenhuis et al., 2007).

\footnotetext{
* Corresponding author; e-mail: andrea.digiulio@uniroma3.it
} 
Members of the family Syrphidae, also known as hover flies or flower flies, are nearly ubiquitous and belong to one of the largest groups of Diptera [about 6,200 known species, 828 of which are present in Europe (Pape et al., 2015)], especially known for their unsurpassed textbook examples of Batesian mimicry of Hymenoptera (Speight, 2008). Within this family, Microdontinae is the group with highest diversity of myrmecophiles, with about 110 documented records of associations with ants (Reemer, 2013). Most of these species are known to be social parasites or predators of ant brood, with only one being a parasitoid (Pérez-Lachaud et al., 2014). The most representative genus is Microdon Meigen, 1803, the larvae of which are social parasites associated with five ant subfamilies: Ponerinae, Dolichoderinae, Pseudomyrmecinae, Myrmicinae and Formicinae (Reemer, 2013). Although Microdon is a speciose genus of about 300 species mainly occurring in South America, it is still poorly known, with the majority of studies on this genus on a few species mainly from Europe and North America (Wheeler, 1924; Akre et al., 1973; Garnett et al., 1990; Rotheray, 1991; Barr, 1995; Doczkal \& Schmid, 1999; Schönrogge et al., 2002; Schmid, 2004; Gammelmo \& Aarvik, 2007; Speight \& Sarthou, 2011; Witek et al., 2011; Wolton, 2011; Speight, 2013). In Europe only six species are known: $M$. analis (Macquart, 1842), M. major (Andries, 1912), M. devius (Linnaeus, 1761), M. miki Doczkal \& Schmid, 1999, M. mutabilis (Linnaeus, 1758) and M. myrmicae Schönrogge et al., 2002 (Doczkal \& Schmid, 1999; Schmid, 2004; Speight, 2004, 2013; Gammelmo \& Aarvik, 2007). Another species from Bulgaria, M. sophianus Drensky, 1934 is listed in Fauna Europaea (Speight, 2004). However, it was never recorded again after description and the validity of this species is still under discussion. Of these, M. mutabilis and M. myrmicae can be identified based only on the characters of the pre-imaginal instars, like the length of the puparium and spiracular tubercles (Schönrogge et al., 2002). The validity of these species is also based on their different ecologies and especially their host ants: Microdon mutabilis has been known as a parasite of Formica lemani Bondroit, 1917, whereas $M$. myrmicae was mainly found in the nests of Myrmica scabrinodis Nylander, 1846 and sometimes those of other species of Myrmica (Schönrogge et al., 2002; Speight, 2013). Adult morphology of European Microdon has been thoroughly studied, whereas their myrmecophilous maggots and their behavioural relationships with ants is much less well known.

Adult hover flies feed mostly on flowers, sugary liquids or decaying plant matter and their apodous larvae show a huge spectrum of feeding habits ranging from phytophagous, mycophagous, saprophagous to predators and parasitoids. Microdon larvae are highly modified, slug-like predators of ant larvae (Garnett et al., 1990), one of the most striking examples of feeding specialization in this group. Like other obligate myrmecophiles, these larvae are able to successfully infiltrate into ant colony, feed on the ant brood and also gain other benefits like shelter, favourable climatic conditions and protection from predators (Akre et al., 1973). Since these larvae live hidden in ant nests, showing complex interactions with their hosts, the study of their biology and behaviour is challenging. This is why the life cycle of most Microdon species is still undescribed.

The few descriptive works dealing with the larvae of $M i$ crodon generally provide only few morphological details of last instar larvae and puparia (Wheeler, 1908; Rotheray, 1991; Schmid, 2004; Gammelmo \& Aarvik, 2007; Speight \& Sarthou, 2011; Wolton, 2011). The only accurate available description is that of Garnett et al. (1990), in which the authors describe and illustrate in detail eggs, larvae and puparia of four North-American species (M. albicomatus Novak, M. cothurnatus Bigot, M. piperi Knab, M. xanthopilis Townsend).

However, all previous studies are based only on light microscopy and mainly illustrate the general habitus, while scanning electron micrographs are seldom provided (Akre \& Paulson, 1993; Witek et al., 2011).

In this work we describe in detail all the immature stages (egg, larva and pupa) of Microdon mutabilis using light, fluorescence and scanning electron microscopy. Our aim is to increase the information on this fascinating group of hoverflies and provide a modern morphological standard for the immature characters that can be used as a reference for further descriptions (or re-descriptions) of other species of Microdon, and for a discussion of the immature taxonomy of this group.

\section{MATERIALS AND METHODS}

\section{Material examined}

This study is based on the analysis of 44 specimens of Microdon mutabilis (10 eggs, 10 first instar larvae, 4 second instar larvae, 10 third instar larvae and 10 puparia). Second and third instar larvae and pupae were collected at Pisoniano (Latium, Central Italy) between April and September 2015 (Table 1) from inside the underground nests of Formica cunicularia (Latreille, 1798), which are easily recognizable by their small earth mounds; eggs and first instar larvae were obtained in the laboratory during the rearing described below. The material is preserved in the A. Di Giulio collection (Rome, Italy).

\section{Field sampling and captive breeding}

The field sampling was carried out in a small area of wet grassland (Pisoniano, Latium, Central Italy), used sporadically for grazing. In April 2015, respectively 72 pupae and 44 pupae were found in two different nests (Table 1). All pupae were attached to grass stems emerging from the nests.

This material was transferred to the laboratory and kept in cages $(40 \times 30 \mathrm{~cm})$, at room temperature $\left(24-27^{\circ} \mathrm{C}\right)$. Each cage was provided with a container full of earth, taken from the original ant nest, on the surface of which the pupae were placed. Periodically this arena was humidified with distilled water. An artifi-

Table 1. Specimens collected at Pisoniano (Latium, Central Italy).

\begin{tabular}{cc}
\hline Date of collection & Specimens collected \\
\hline $09 / 04 / 2015$ & 72 pupae +15 puparia \\
$17 / 04 / 2015$ & 44 pupae \\
$26 / 06 / 2015$ & 1 puparium \\
$26 / 06 / 2015$ & 4 second instar \\
$06 / 08 / 2015$ & 6 puparia \\
$31 / 08 / 2015$ & 39 puparia \\
$01 / 09 / 2015$ & 2 puparia +39 third instar \\
\hline
\end{tabular}


cial ant nest with ants from the original $F$. cunicularia host colony was installed next to the cage with the Microdon pupae. Each nest consisted of a box lined with plaster, connected to an external feeding arena via a plastic tube. The feeding arena (plastic container without lid and with the inner sides treated with Fluon) was inserted inside the cage with the fly pupae.

Flies started to emerge almost synchronously from puparia 14 days after they were collected, and immediately mated. Eggs were laid about 4 days after mating, and the preferred oviposition site was the ant feeding arena. Furthermore, several M. mutabilis adults tried repeatedly to enter the ant nest through the plastic tube to the feeding arena, but were immediately recognized and killed by $F$. cunicularia ants.

Egg masses were collected using a fine brush, isolated in sterile vials, and incubated at room temperature in a humid chamber. Larvae started to hatch about 8 days after laying, but none of them reached the second instar.

Only 4 second instar larvae were found in the field at the end of July. Three were immediately fixed and one was reared in the laboratory to observe and record its feeding behaviour (Supplementary file 2), as described below (see Results). In September, 39 third instar larvae were found; 6 were kept alive for 2 months and put in a cylindrical artificial nest with about 50 workers of $F$. cunicularia plus ant larvae and pupae from the same nest. Interestingly, the ant workers aggregated and stayed on the dorsal surfaces of the syrphid larvae (up to 6-8 workers on one larva) as well as on the piles of their own brood.

\section{Focused Ion Beam/Scanning Electron Microscopy (FIB/SEM)}

Eggs, larvae (all instars) and puparia of M. mutabilis were examined using a Dual-Beam (FIB/SEM) Helios Nanolab (FEI Company, Eindhoven, The Netherlands) at the L.I.M.E. (University of Roma Tre, Rome, Italy). This instrument incorporates both a focused ion beam (FIB) and a scanning electron beam (SEM) in the same microscope. The standard dual-beam column configuration consists of a vertical electron column with a $52^{\circ}$ tilted ion column (typically employing a gallium, Ga source) both focused on the same point in the sample. This combination allows one to selectively ablate parts of a sample using the ion beam, and to observe and take high resolution images of a cross-section of the surface using the electron beam. This technique was used to investigate the internal structure of the processes of the marginal band of larvae, while the FIB/SEM was operated only with the SEM column to acquire high resolution images of the other structures.

Samples were prepared as follows: Larvae were immersed in $70 \%$ ethanol and then gradually dehydrated by placing in higher concentrations of ethanol up to $100 \%$, with intervals of $10 \mathrm{~min}$ between each step. Then they were critical-point dried using a Bal-Tec CDP 030, mounted on double-sided carbon discs on standard stubs and gold sputtered using an Emitech K550 unit.

\section{Light microscopy}

An optical microscopy analysis was carried out on ten slidemounted first instar larvae as follows: Specimens preserved in $70 \%$ ethanol were first rehydrated in 3 descending consecutive baths (ethanol $50 \%, 20 \%, 10 \%$ ), for about $10 \mathrm{~min}$ each, and washed in distilled water. Afterwards, they were placed in a $10 \%$ solution of $\mathrm{KOH}$ for about $30 \mathrm{~min}$ at $30^{\circ} \mathrm{C}$. To facilitate the penetration of $\mathrm{KOH}$ into the body of the larvae, their skins were perforated using a minute probe. Later the specimens were transferred to hot lactic acid for $30 \mathrm{~min}$. The larvae were pressed to remove their internal contents. When sufficiently clean and clear they were transferred to $10 \%$ ethanol and dehydrated through a series of ethanol washes $(20 \%, 50 \%, 70 \%, 85 \%, 95 \%, 100 \%)$ of 10 min each. Later, the specimens were immersed in Clove Oil for at least $1 \mathrm{~h}$ and finally mounted in Canada Balsam on a slide and put in an oven at $40^{\circ} \mathrm{C}$ for 3 days. These preparations were observed using an Olympus BX51 light microscope.

Measurements reported in the descriptions of eggs, first and third instar larvae and pupae are means of 10 specimens, except for second instar larvae for which only 3 were measured.

\section{Histology}

For the histological analysis, first instar larvae were killed in Bouin's solution, dehydrated in a graded ethanol series (as describe above) and embedded in paraffin. The small paraffin blocks were serially cut using a rotary microtome into sections $7 \mu \mathrm{m}$ thick. Sections were stuck on slides using albumin and stained with haematoxylin and eosin. Slides were studied using an Olympus BX51 light microscope and a fluorescence microscope Zeiss Axio Zoom V16.

\section{Locomotion}

A third instar larva of M. mutabilis was placed in an empty small Petri dish ( $5 \mathrm{~cm}$ of diameter). The locomotion movies were shot using an Olympus OM-D camera. In some videos the third instar larva was filmed through the bottom of the Petri dish in order to observe the movement of the muscular foot (Supplementary file 1).

\section{Feeding behaviour}

A second instar larva of M. mutabilis was placed in a small Petri dish (5 $\mathrm{cm}$ of diameter) with a wet disk of filter paper on the bottom together with 5 larvae and pupae of Formica cunicularia. The Petri dish was observed using an Olympus SZX2-ILLT stereomicroscope connected to an Olympus camera U-CMAD3. The film of the feeding behaviour was obtained using software CellD (Supplementary file 2).

\section{Acronyms}

In the description we used the following terminology and nomenclature of anatomical parts proposed by Courtney et al. (2000) for the larvae of Diptera and those of Garnett et al. (1990) for larvae of Microdon.

Ant - antenna; AO - anal opening; ASn - anterior sensillum; Atr - atrium; Bs - base; DCorn - dorsal cornua; Dm - dome; $\mathrm{DmL}$ - dorsomedial lobe; Dn - denticles; EF - external furrow; EL - external lobe; LabScl - labial sclerite; LF - lateral furrow; LLb - lateral lobe; MA - micropyle area; Md - mandibles; MF - medial furrow; MG - medial groove; $M L$ - medial lobe; $\mathrm{MrB}$ - marginal band; MrS - marginal stripe; MxPlp - maxillary palp; $\mathrm{PC}$ - pseudocephalon; $\mathrm{Pr}$ - pore; $\mathrm{PSn}$ - posterior sensillum; $\mathrm{PSprTu}$ - posterior spiracular tubercle; $\mathrm{Scl}$ - scale; ScS - scalloplike sculpticels; SprPlt - spiracular plate; $\mathrm{SpS}$ - spiniform setae; SRP - simple reticulation process; TntScl - tentoropharyngeal sclerite; TS - thoracic sterna; VLb - ventral lobe; WMrB - waves of marginal band.

For structures not described previously we have used new terminology that refers to their peculiar shapes.

AS - arborescent structure; ASl - alveolate slope; $\mathrm{Cr}$ - crater; FB - fringed brush; FP - fused process of marginal band; FS flower-like sensilla; IJ - imbricate joint; MD - medial depression; MDP - multiperforate and depressed plate; PL - petal-like lobe; $\mathrm{PP}$ - polygonal plate; ReFis - respiratory fissure; $\mathrm{RH}$ - respiratory hole; RP - radial projection; SC - smooth crown; VP - volcano-like process. 

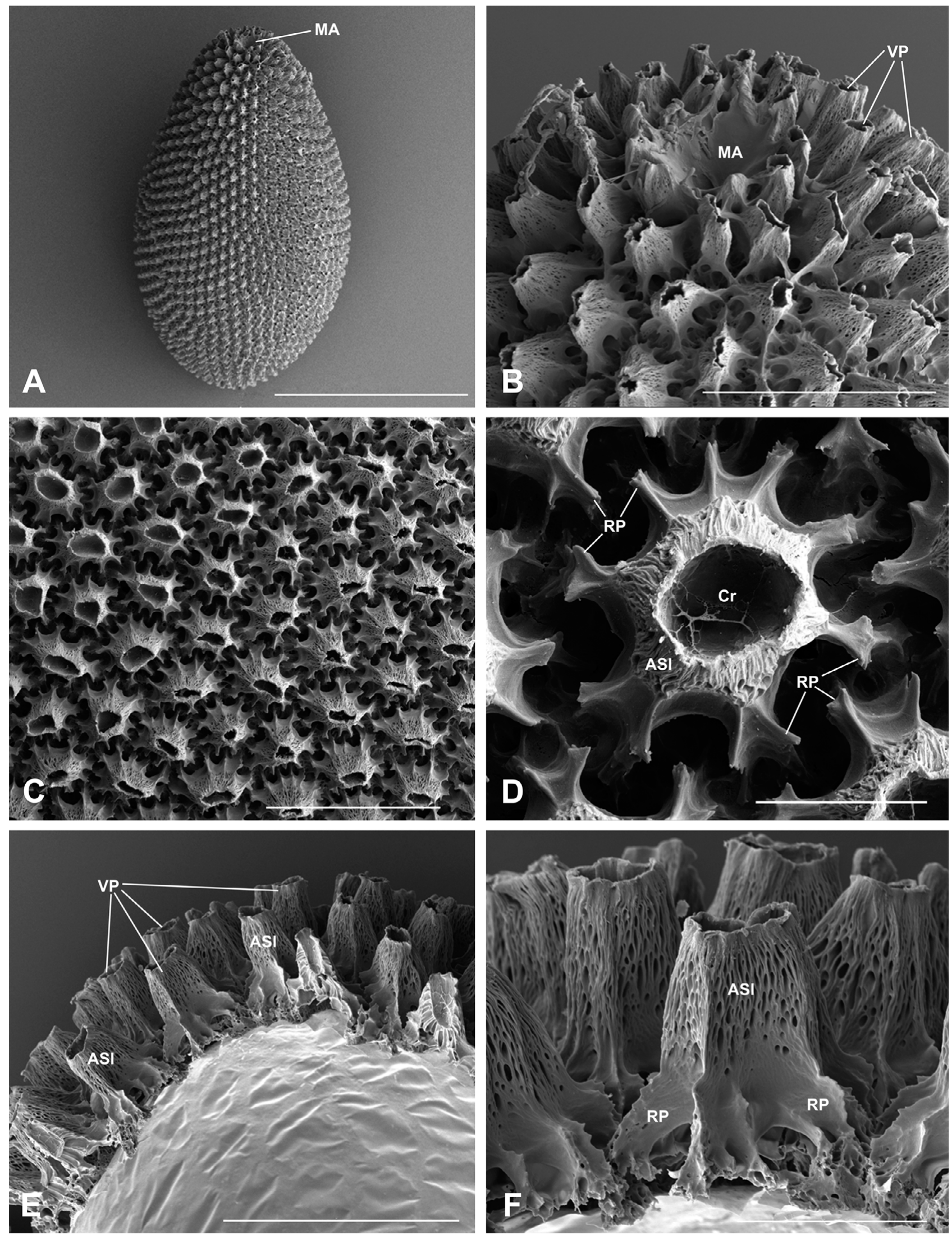

Fig. 1. Egg of Microdon mutabilis: A - lateral view; B - detail of anterior pole with micropyle area; C - chorion microsculpture of volcanolike processes; $D$ - dorsal view of a single volcano-like process; $E$ - section of chorion showing internal surface; $F$ - lateral view of a volcano-like process. ASI - slveolate slope; $\mathrm{Cr}$ - crater; MA - micropyle area; RP - radial projection; VP - volcano-like process. Scale bars: $A=500 \mu \mathrm{m} ; B, C, E=100 \mu \mathrm{m} ; D=20 \mu \mathrm{m} ; F=30 \mu \mathrm{m}$. 
Table 2. Measurements (in $\mathrm{mm}$ ) of 10 first instar larvae of M. mutabilis. TL - total length; $A L$ - abdomen length; $A W$ - abdomen width; $\mathrm{HL}$ - head length; AMLL - antennomaxillary lobe length; CSL cephaloskeleton length; STL - spiracular tubercle length; STW spiracular tubercle width. Specimen 7 lacked a pseudocephalon.

\begin{tabular}{ccccccccc}
\hline Specimens & $\mathrm{TL}$ & $\mathrm{AL}$ & $\mathrm{AW}$ & $\mathrm{HL}$ & $\mathrm{AMLL}$ & $\mathrm{PC}$ & $\mathrm{STL}$ & $\mathrm{STW}$ \\
\hline 1 & 1.57 & 1.23 & 0.8 & 0.36 & 0.15 & 0.29 & 0.28 & 0.18 \\
2 & 1.54 & 1.06 & 0.74 & 0.44 & 0.15 & 0.28 & 0.27 & 0.17 \\
3 & 1.61 & 1.2 & 0.82 & 0.35 & 0.13 & 0.27 & 0.28 & 0.15 \\
4 & 1.35 & 1.03 & 0.8 & 0.35 & 0.13 & 0.27 & 0.27 & 0.18 \\
5 & 1.35 & 1.00 & 0.71 & 0.34 & 0.1 & 0.24 & 0.25 & 0.18 \\
6 & 1.63 & 1.23 & 0.83 & 0.34 & 0.13 & 0.28 & 0.19 & 0.17 \\
7 & 1.34 & 1.14 & 0.91 & 0.24 & - & - & 0.29 & 0.17 \\
8 & 1.57 & 1.23 & 0.77 & 0.4 & 0.13 & 0.28 & 0.29 & 0.17 \\
9 & 1.46 & 1.14 & 0.83 & 0.35 & 0.12 & 0.29 & 0.27 & 0.17 \\
10 & 1.55 & 1.21 & 0.77 & 0.36 & 0.11 & 0.29 & 0.27 & 0.16 \\
Media & 1.50 & 1.15 & 0.80 & 0.35 & 0.13 & 0.28 & 0.27 & 0.17 \\
Dev.st & 0.11 & 0.08 & 0.05 & 0.05 & 0.02 & 0.01 & 0.03 & 0.01 \\
\hline
\end{tabular}

\section{RESULTS}

\section{Description}

Egg (Fig. 1) mean width $=524.84 \mu \mathrm{m}, \mathrm{sd}=27.05$; mean length $=1.15 \mathrm{~mm}, \mathrm{sd}=0.15(\mathrm{n}=10)$. Elongate, ovoid (Fig. 1A), circular in transverse section, slightly tapered towards anterior end, white in colour. Micropyle funnel-shaped, with smooth internal surface (Fig. 1B). Chorion entirely covered with a distinctly raised microsculpture (Fig. 1C), composed of many regularly spaced "volcano-like" conical processes (Fig. 1D), with a deep, smooth apical depression (Crater) and alveolate steep slopes (Figs 1E-F), deeply wrinkled, set on a smooth stellate base, with 7-9 radial ridged projections (Figs 1D-C); semicircular incision between two adjacent basal projections; chorionic processes densely, puzzle-like packed, separated by deep grooves (Figs 1D-C).

First instar (Figs 2, 3, 4, 5, 6, 7, 8, 11) mean body width $=0.80 \mathrm{~mm}, \mathrm{sd}=0.05$; mean body length $=1.50 \mathrm{~mm}, \mathrm{sd}=$ $0.11(\mathrm{n}=10)$ (Table 2).

General features. Body shape sub oval, anteriorly tapering, flattened, slightly convex dorsally, with conspicuous pseudocephalon (Figs 2A1-A2), partially or totally retractable. Posterior spiracular tubercle thin and elongate, distinctly sclerotized, light brown, contrasting with the whitish colour of the body (Figs 5A-D).

Body features. Body oval in dorsal view, distinctly convex dorsally, flattened ventrally. Anterior part slightly narrower than posterior and bearing 2 raised lobes (Figs 2A1A2). Marginal band, surrounding the whole perimeter of the body except for the anteromedial furrow, distinctly separates dorsal from the ventral side of the body (Figs 2A1-A2-A3). Dorsal surface rough, bumpy, transversely corrugated, deeply marked by subequal, conical, rugulose structures (Fig. 2A1-B1, 3A). Thoracic and abdominal tergites fused and not recognizable (Fig. 2A1). Sculpticels on anterior part of the body distinctly pointed and posteriorly directed (Fig. 2B1). Four longitudinal grooves present dorsally (Fig. 2A1) dividing dorsal body surface into 5 main longitudinal fields: 1 medial, 2 lateral and 2 external marginal fields. Medial field partially divided into 2 halves by a longitudinal, medial line (ecdysial suture?).
Dorsal surface with regularly spaced "flower-like" sensilla (Fig. 3A): medial field with 2 longitudinal rows of 9 sensilla; each lateral field with 13 sensilla arranged in 2 rows (7 along lateral groove and 6 along medial groove). Each marginal field with 1 row of 10 sensilla. Each sensillum (Fig. 3C) composed of a cylindrical base, with many imbricate, thick sculpticels, apically with a medial flower-like structure with a variable number (5-10) of lobes, pointed at tip, encircling a medial dome with a lateral pore. Ventral surface is wide, soft (Fig. 2A3), transversally multi-folded, markedly furrowed by a deep, longitudinal, medial groove (Figs 2A3, 3B), running along abdominal sterna and surrounded by a hairy marginal stripe. Ventral surface covered by pointed microsculpture medially, finely pilose on sides. The thoracic sterna possibly represented by the first 3 narrow anterior segments, separated by deep transverse furrows (Fig. 2B3). First 7 abdominal sterna, possibly recognized by the presence of 7 transverse rows of 6 flowerlike sensilla, 3 on each side of medial groove. Ventral flower-like sensilla (Fig. 3D) similar to dorsal ones except for flat, soft, unsculptured base and flat, thin, distinctly pointed lobes. Suboval marginal stripe covered by elongated hairs (Fig. 2A3), posteriorly directed and bearing some small flower-like sensilla. Anal opening wide, transverse, subtriangular (Fig. 2A3). Four flower-like sensilla posterior to the anus.

Pseudocephalon and cephaloskeleton. Pseudocephalon with 2 pairs of lobes (Figs 2B1-B2): a - 2 anterodorsal antennomaxillary lobes bulging and distinctly separated from one another, each apically bearing a 2-segmented antenna and 1 -segmented maxillary palpus; $b-2$ lateral labial lobes representing the walls of a medial atrium; floor of atrium delimited by a minor ventral lobe (Fig. 2B3); each lateral lobe, with pseudocephalon retracted, encircling the outer side at the base of antennomaxillary lobe; 2 pairs of sensorial organs on dorsal surface of pseudocephalon (Fig. 4A), 1 anterior (Fig. 4C) and 1 posterior (Fig. 4E), each composed of clusters of 4 short and 1 long trichoid sensilla emerging from bulbous, hollow base; sensory organs on posterior pair closer to the midline than anterior pair. Dorsal surface of pseudocephalon with heterogeneous microsculpture (see Fig. 4A): apical part has imbricate sculpticels, each one posteriorly multi-frayed; at level of anterior sensorial organs, dorsal microsculpture represented by distinctly separated raised plates, surrounding a medial smooth area. Sides of pseudocephalon smooth. Ventral surface of pseudocephalon totally covered by a dense carpet of thin trichoid structures (Fig. 2B3); lateral lobes medially covered by elongate brush-like structures, each consisting of a long spinulate basal stem bearing an apical tuft of setae. Cephaloskeleton heavily sclerotized (Figs 5A-B-C) divided into 3 major parts (Fig. 6A1): anterior paired mandibles, posterior tentoropharyngeal sclerite and anteroventral labial sclerite. Mandibles separated posteriorly, but convergent and completely fused anteriorly, forming a unique cutting apparatus (Fig. 6A3). Posterior part of each mandible ventrally bearing 6 conical denticles, reducing in size from posterior to anterior, each with an inwardly 

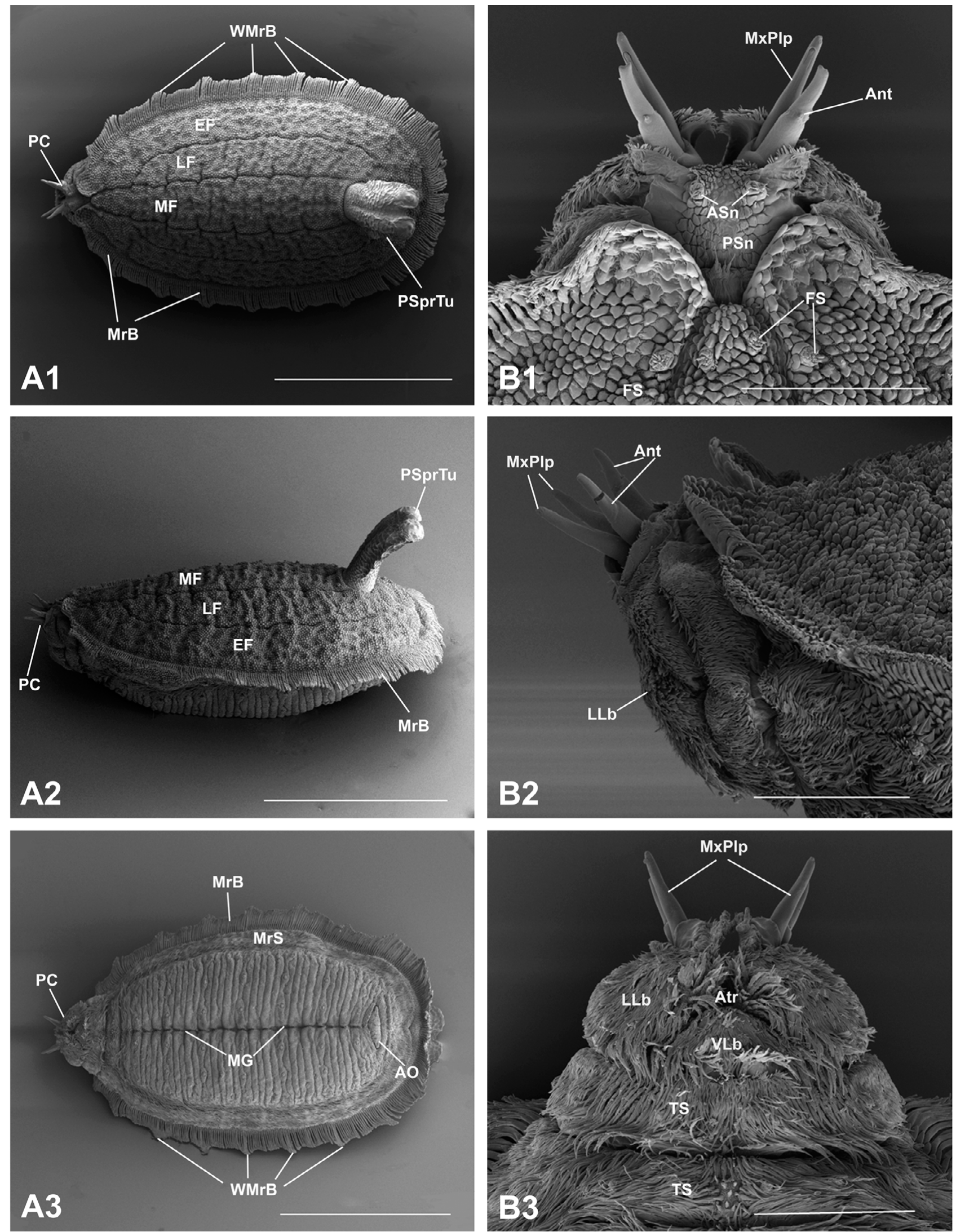

Fig. 2. First instar larva of Microdon mutabilis: A - habitus: A1 - dorsal view; $A 2$ - lateral view; $A 3$ - ventral view; B - pseudocephalon: B1 - dorsal view; B2 - lateral view; B3 - ventral view. Ant - antenna; AO - anal opening; ASn - anterior sensillum; Atr - atrium; EF - external furrow; FS - flower-like sensilla; LLb - lateral lobe; LF - lateral furrow; MF - medial furrow; MG - medial groove; MrB - marginal band; MrS - marginal stripe; MxPIp - maxillary palp; PC - pseudocephalon; PSn - posterior sensillum; PSprTu - posterior spiracular tubercle; TS - thoracic sterna; VLb - ventral lobe; WMrB - waves in the marginal band. Scale bars: A1, A2, A3 = 500 $\mu \mathrm{m} ; \mathrm{B} 1, \mathrm{~B} 2, \mathrm{~B} 3=100 \mu \mathrm{m}$. 

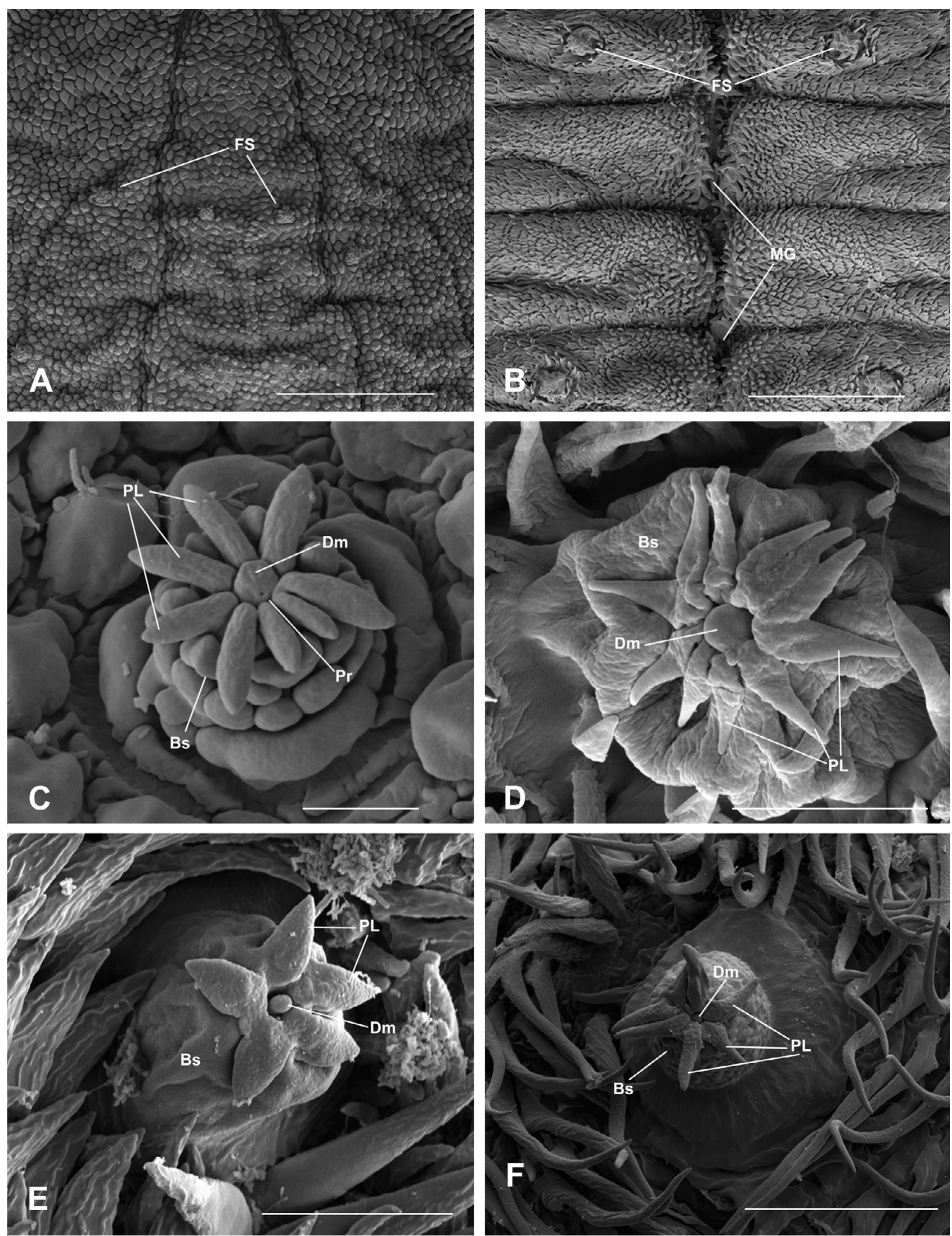

Fig. 3. Flower like sensilla of Microdon mutabilis: A-D - first instar larva: A, C - dorsal view; B, D - ventral view; $E$ - second instar larva, ventral view; $\mathrm{F}$ - third instar larva, ventral view. Bs - base; Dm - dome; FS - flower-like sensilla; MG - medial groove; PL - petal-like lobe; $\mathrm{Pr}-$ pore. Scale bars: $\mathrm{A}, \mathrm{B}=100 \mu \mathrm{m} ; \mathrm{C}=10 \mu \mathrm{m} ; \mathrm{D}=5 \mu \mathrm{m} ; \mathrm{E}=20 \mu \mathrm{m} ; \mathrm{F}=50 \mu \mathrm{m}$. 
curved, sharp apex (Fig. 6A3). Anterior part shaped into a rounded, thin, strongly serrated blade (Figs 6A2-A3), with 10 large, laterally flat, triangular teeth, each bidentate at apex (Fig. 6A2): anterior teeth wider and sharper. Hypopharynx fused posteriorly with tentoropharyngeal sclerite, more heavily pigmented than mandibles. Dorsal cornua of tentoropharyngeal sclerite elongate, about $1 / 2$ length of ventral portion of sclerite (Fig. 6A1).

Cephaloskeleton retracted inside the pseudocephalon in resting position (Fig. 5A); it is protracted out from atrium while feeding. Labial sclerite ventral to mandibles, anteroventral to tentoropharyngeal sclerite, composed of a pair of external lobes, encircling the base of mandibles laterally, a pair of dorsomedial lobes, and a medial lobe anteriorly denticulated, with 8 small teeth (Fig. 5C); maxillae anterodorsal to labial sclerite, lightly pigmented and flattened.

Posterior spiracular tubercle. Elongate, cylindrical, strongly sclerotized (Fig. 5D) structure, emerging perpendicularly from posterodorsal part of abdomen (Fig. 2A2), with apical part wider than basal and medially incised, and sides carinated and sharply edged (Fig. 7A2). Main part of tubercle furrowed longitudinally, both anteriorly and posteriorly, by a deep longitudinal groove separating 2 subparallel structures, each circular in section and containing one tracheal tube (Figs 5D, 7A1-A2). Wall of spiracular tubercle very thick and multi layered (Figs 11A1-A2). Fluorescence microscopy showing the presence of resilin in the external layer (Figs 5E-F). Surface of spiracular tubercle with peculiar microsculpture, completely covered by imbricate, sclerotized scales with an indented superior edge (Figs 7A1-A2); dimensions of scales decreasing basally. Apex of tubercle with 2 circular smooth plates, slightly convex, each with 1-2 respiratory narrow fissures that communicate with the distal part of tracheal trunks (Fig. 7A1). The remaining 2 tracheae separated for their entire length, each serving one side of the body (Fig. 5D).

Marginal band. Appearing as an undulated fringe of elongate, parallel, radially projecting processes, continuously surrounding the body laterally and posteriorly, only absent on the small V-shaped anterior part of the tergum (Figs 2A1, 8A1). Length of processes regularly varying, showing 8 waves on each side (Figs $2 \mathrm{~A} 1-\mathrm{A} 3,8 \mathrm{~B} 1$ ). At the apices of the 8 waves, the longest processes appear thicker as a result of partial lateral fusion of 2 adjacent simple processes (Figs 8B2-B3), and bear dorsally one apical and one subapical spiniform seta (Fig. 8A2). Each simple process composed of an elongate stem and an apical fringed brush (Fig. 8A3); the stem showing two very different surfaces: dorsal surface apparently articulated with 4-5 imbricated joints, the last one fringed apically (Fig. 8A3); ventral surface completely smooth (Fig. 8B3). Cross sections of these structures (Fig. 8B3) showing complex cuticular projections.

Second instar (Figs 3, 7, 9, 10, 11, 13) mean body width $=0.35 \mathrm{~mm}, \mathrm{sd}=0.11$; mean body length $=0.38 \mathrm{~mm}, \mathrm{sd}=$ $0.11(\mathrm{n}=3)$.

Second instar differs from first instar as follows:
Dorsal surface rough, deeply marked by sub equal, irregularly wrinkled microsculpture (Figs 9B-F), with some scattered, round and multiperforate depressed plates (Figs 9B-C-D), which are slightly rugulose. Dorsal reticulation processes abundant, forming an irregular pattern of intersecting rows (Fig. 9A). Each simple reticulation process crown-shaped (Figs 9C-E), bearing 4-5 extended, pointed projections. Longitudinal dorsal grooves reduced to a couple of medial furrows (Fig. 9A). Fewer flower-like sensilla than in first instar larvae, but similar in shape (Fig. 3E). External perimeter of abdomen resembling a thick, raised, cuticular frame, completely covered by pointed, rugulose and scallop-like sculpticels (Figs 10A1-A2). Pseudocephalon small compared to the rest of body. Posterior spiracular tubercle short, dome-shaped, almost hemispherical, reddishbrown (Figs 7B1-B2; 13A1-A2), deeply sulcated anteriorly and posteriorly by an incomplete medial depression (Figs 7B1-B2). Spiracular tubercle surface covered by many independent polygonal plates, with serrate margins, fitting together like pieces of a puzzle; subapical plates irregular in shape (Figs 7B1-B2); polygonal plates representing flattened apices of more complex cuticular arborescent structures, each characterized by a multi-branched stem emerging from the internal surface of a spiracular tubercle; length of stems becoming shorter from base to apex (Figs 11B1-B2). Apical surface of spiracular tubercle smooth and butterfly-shaped with irregular margins, furrowed by 4 groups of narrow respiratory fissures radially disposed and medially with two round holes (Figs 7B1-B2). Mandibles completely separated with no sign of anterior fusion. Each mandible antero-ventrally bearing 15-18 conical sharp, inwardly curved denticles, the 6 anterior ones more flattened and not distinctly bidentate at apex.

Processes on the marginal band short and subequal in length except for pairs of longer processes [on anterior part of body bifurcate at apex (Fig. 10A1)], regularly spaced with 7-10 shorter ones in between (Figs 10A2-A3); each process composed by a smooth, cylindrical stem and a flattened, apical brush; longer processes combined with 3-4 spiniform setae (Fig. 10A3).

Third instar (Figs 3, 6, 7, 10, 11, 12, 13) mean body width $=0.85 \mathrm{~mm}, \mathrm{sd}=0.07$; mean body length $=1.09 \mathrm{~mm}$, $\mathrm{sd}=0.04(\mathrm{n}=10)$.

Third instar differs from second instar as follows:

Body strongly convex dorsally, nearly semi circular in transverse section (Figs 13B1-B2); surface entirely covered by papillary sculpticels without multiperforate and depressed plates. Dorsal reticulation reduced to a narrow, lateral strip along the perimeter of abdomen (Figs 10B1B2, 13B1-B2). Dorsal reticulation processes forming semi circular or polygonal shapes (Figs 13B1-B2). Each reticulation process showing stringy, extended projections (Figs 10B1-B2). Dorsal convex surface with scattered sub circular groups of 5-9 umbrella-like structures (Fig. 12F) with a flattened, wrinkled, circular apex bearing a cylindrical stem. Dorsal grooves absent. Flower-like sensilla similar in shape to those of previous stages, with lobes slightly narrower (Fig. 3F). External perimeter without raised, cu- 

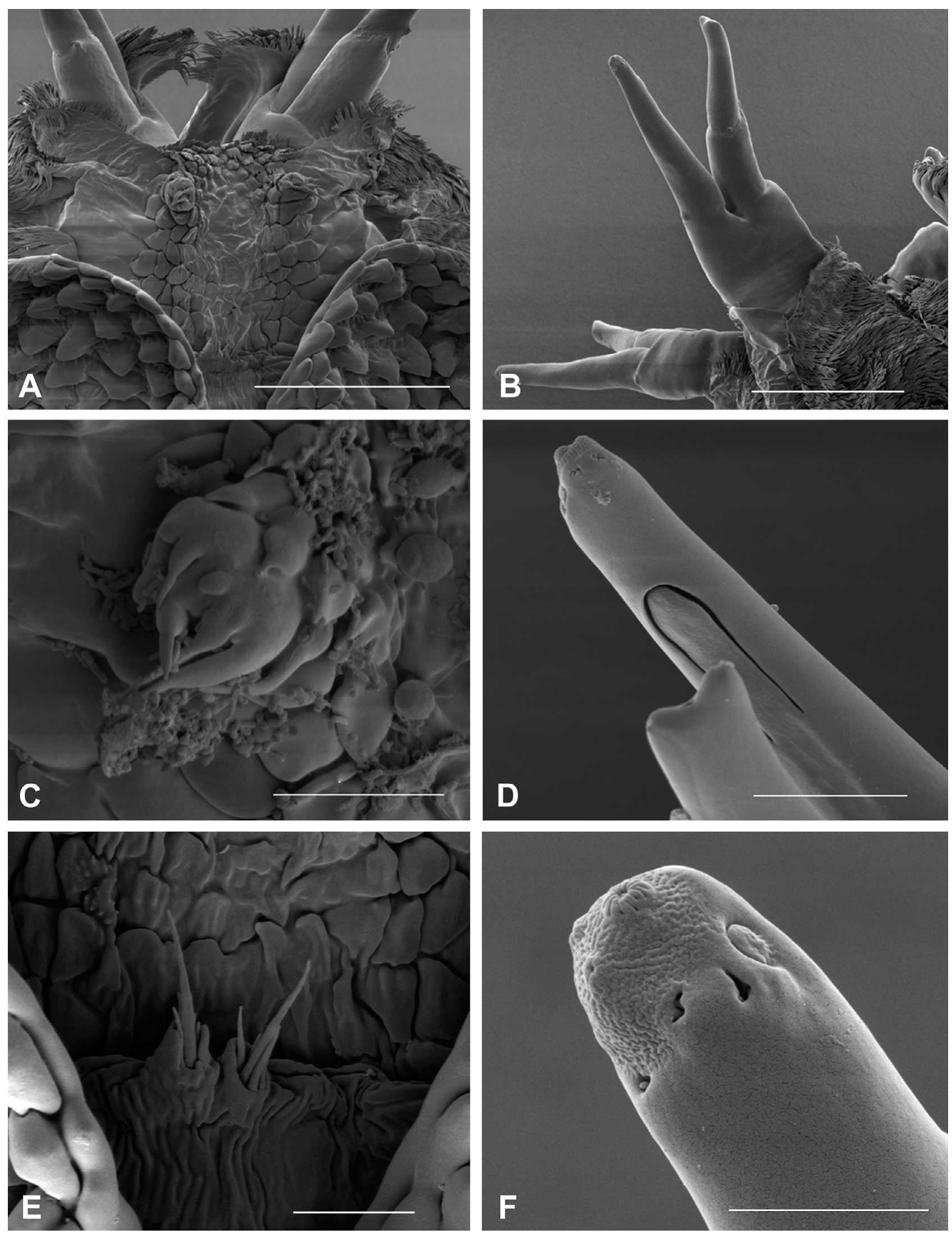

Fig. 4. Pseudocephalon of the first instar larva of Microdon mutabilis: A - dorsal view; B - antennomaxillary lobes, lateral view; C - right anterior sensorial organ; D - distal part of left maxillary palpus, with digitiform sensillum visible; $\mathrm{E}$ - posterior sensorial organs; $\mathrm{F}$ - apex of left maxillary palpus. Scale bars: $A, B=50 \mu \mathrm{m} ; C, D, E=10 \mu \mathrm{m} ; F=5 \mu \mathrm{m}$. 

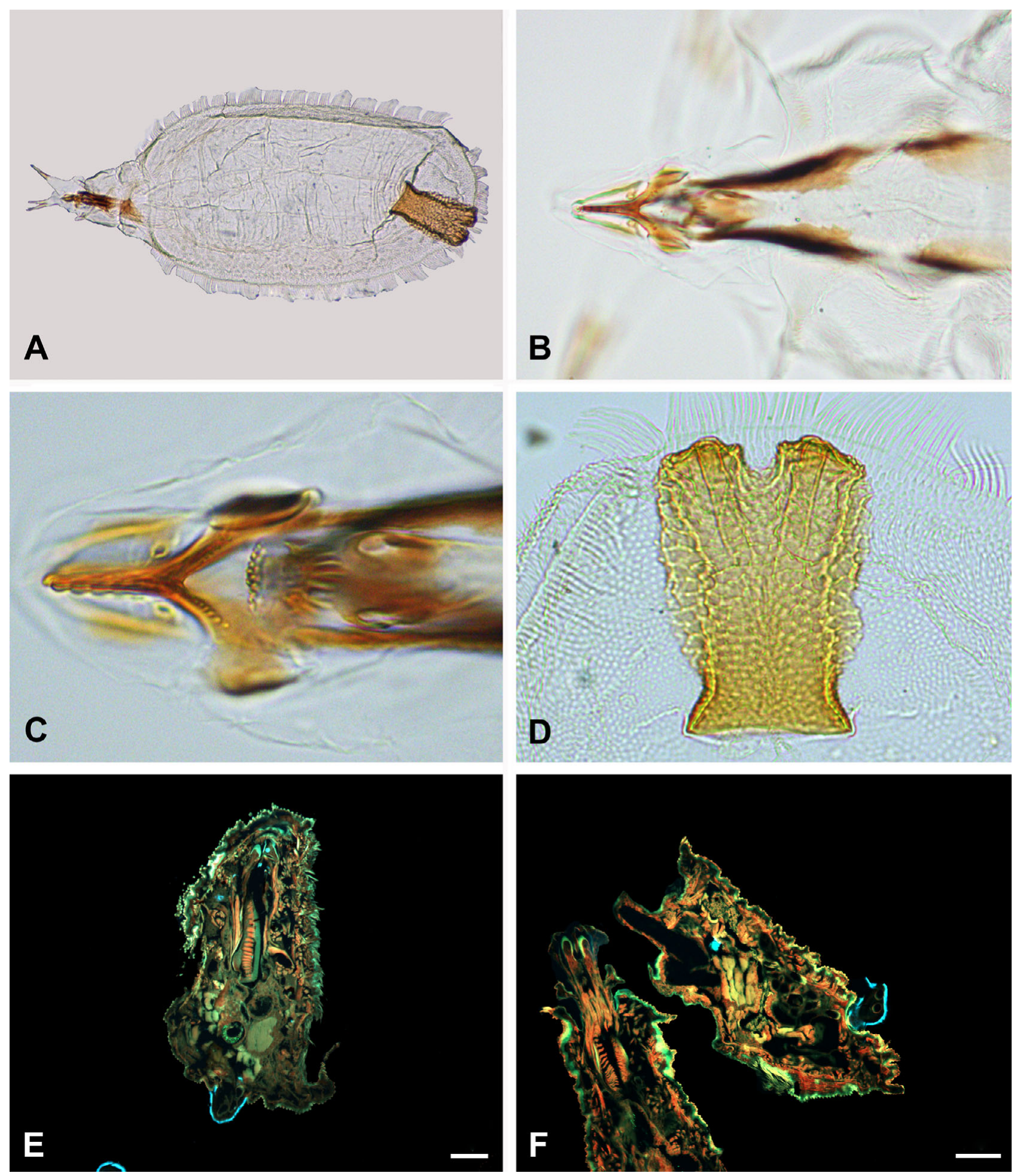

Fig. 5. Light and fluorescence microscopy of first instar larva of Microdon mutabilis: A-D - light microscopy images: A - habitus; B sclerotized cephaloskeleton with visible labial sclerites; $C$ - detail of B; D - posterior spiracular tubercle, dorsal view; E, F - fluorescence microscopy images of longitudinal histological sections with 3 overlaid filters: Dapi, Gfp and Dsred. The Dapi filter is responsible for the blue colour of the external resilin layer in posterior spiracular tubercle. Scale bars: $E, F=100 \mu \mathrm{m}$.

ticular frame. Surface of the posterior spiracular tubercle covered laterally with many polygonal plates; a subapical stripe of irregular plates dividing the apex into 2 halves (Figs 7C1-C2); polygonal plates representing the flattened apices of cuticular cylindrical structures (Figs 11C1-C2). The base of posterior spiracular tubercle encircled by a smooth cuticular crown (Fig. 7C2). Apical surface of posterior spiracular tubercle smooth with irregular margins, furrowed by numerous groups of narrow respiratory fissures, radially arranged (Figs $7 \mathrm{C} 1-\mathrm{C} 2$ ). Mandibles dorsally fused together by a thin membranous belt (Fig. 6B3). Each mandible antero-ventrally bearing 26 conical, sharp, 

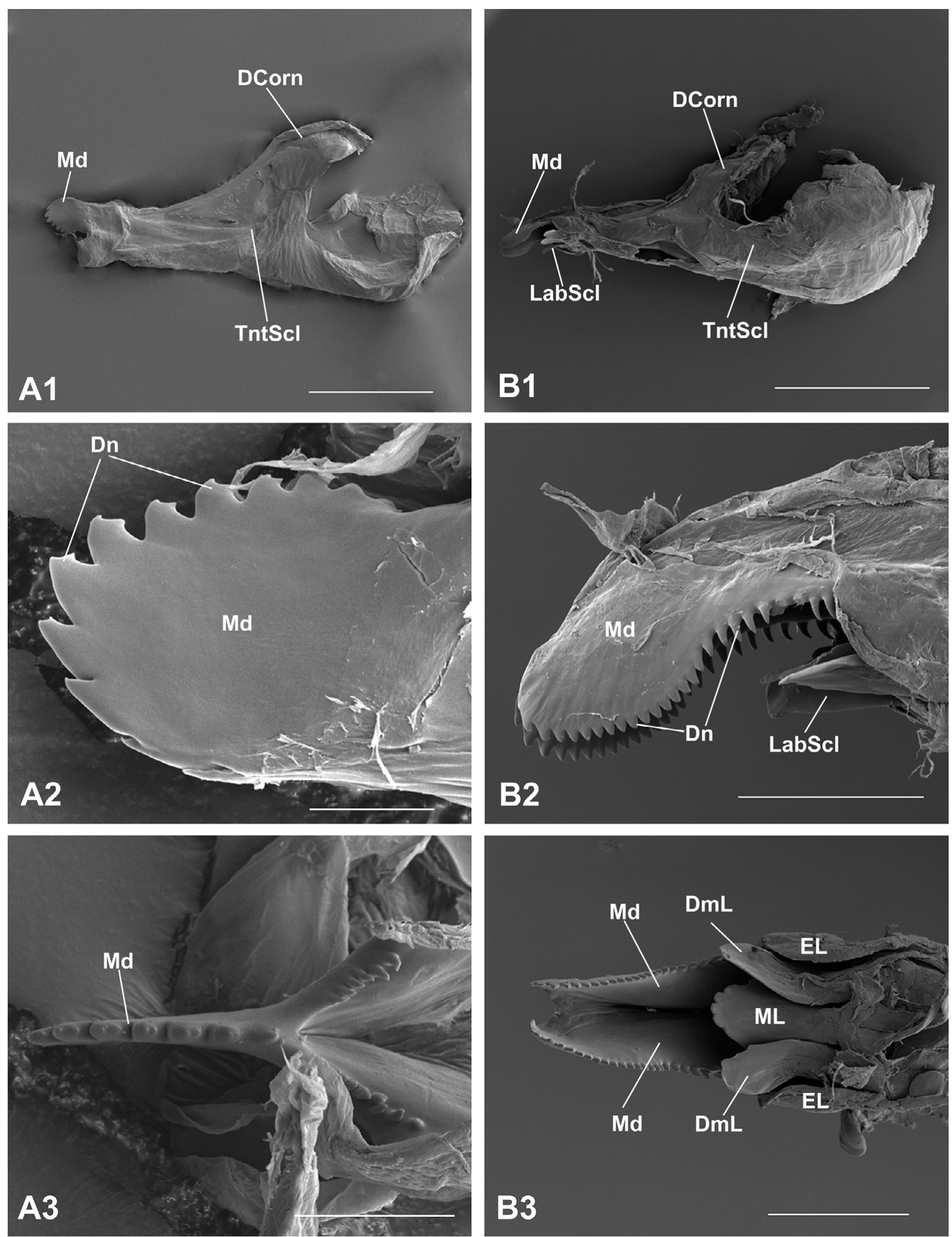

Fig. 6. Cephaloskeleton of Microdon mutabilis: A - first instar larva: A1 - cephaloskeleton, lateral view; A2 - fused mandibles, lateral view; A3 - fused mandibles, ventral view; B - third instar larva: B1 - cephaloskeleton, lateral view; B2 - mandibles, lateral view; B3 - mandibles and labial sclerites, ventral view. DCorn - dorsal cornua; DmL - dorsomedial lobe; Dn - denticles; EL - external lobe; LabScl - labial sclerite; Md - mandibles; ML - medial lobe; TntScl - tentoropharyngeal sclerite. Scale bars: A1, B2, B3 = $100 \mu \mathrm{m} ; \mathrm{A} 2=10 \mu \mathrm{m} ; \mathrm{A} 3=20$; $\mu \mathrm{m} B 1=500 \mu \mathrm{m}$. 

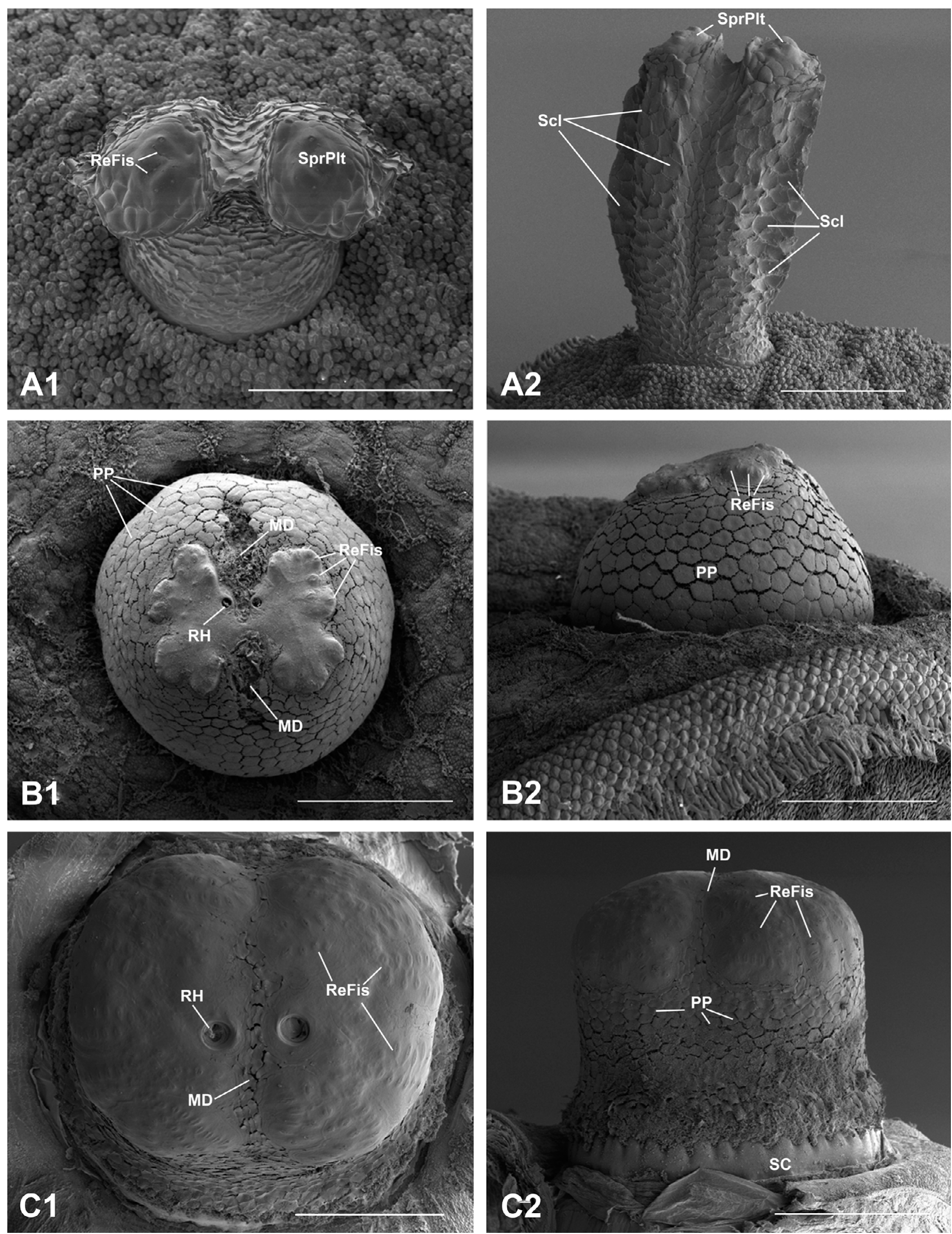

Fig. 7. Posterior spiracular tubercle of Microdon mutabilis: A - first instar larva: A1 - apical view; $A 2$ - anterior view; B - second instar larva: B1 - apical view; B2 - lateral view; C - third instar larva: C1 - apical view; C2 - anterior view. MD - medial depression; PP - polygonal plate; ReFis - respiratory fissure; $\mathrm{RH}$ - respiratory hole; SC - smooth crown; Scl - scale; SprPIt - spiracular plate. Scale bars: A1, A2 = $100 \mu \mathrm{m} ; \mathrm{B} 1, \mathrm{~B} 2, \mathrm{C} 2=400 \mu \mathrm{m} ; \mathrm{C} 1=300 \mu \mathrm{m}$. 

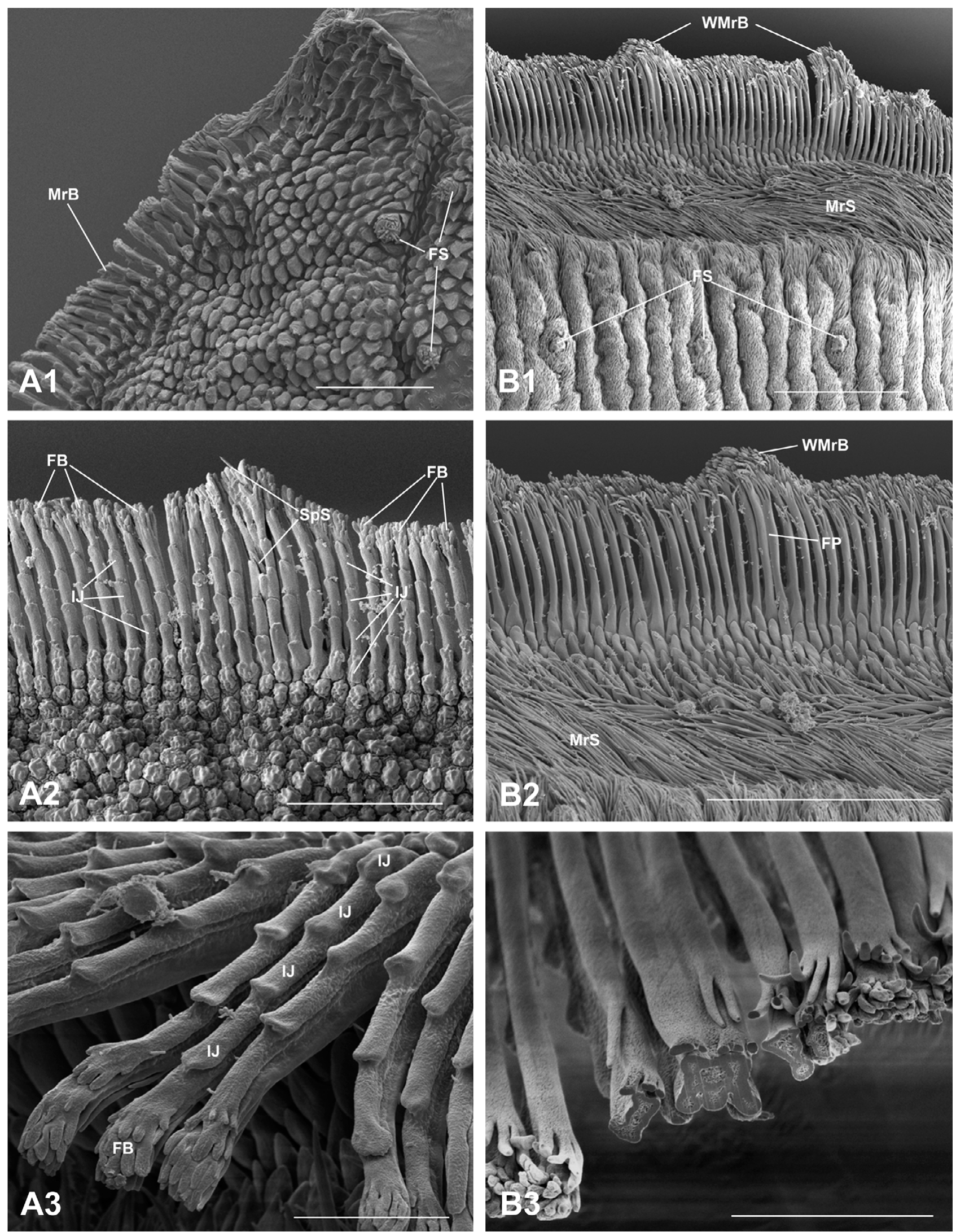

Fig. 8. Marginal band of a first instar larva of Microdon mutabilis: A - dorsal view: A1 - anterior part; A2 - lateral part; A3 - detail of processes, dorsolateral view; B - ventral view: B1 - smooth ventral surface; B2 - detail of the former; B3 - cross section of the apex of a process obtained using a Focused Ion Beam. FB - fringed brush; FP - fused processes; FS - flower-like sensilla; IJ - imbricate joint; $\mathrm{MrB}$ - marginal band; MrS - marginal stripe; SpS - spiniform setae; WMrB - waves in marginal band. Scale bars: A1, A2 = 50 $\mu \mathrm{m} ; \mathrm{A} 3$, $B 3=20 \mu \mathrm{m} ; \mathrm{B} 1, \mathrm{~B} 2=100 \mu \mathrm{m}$. 

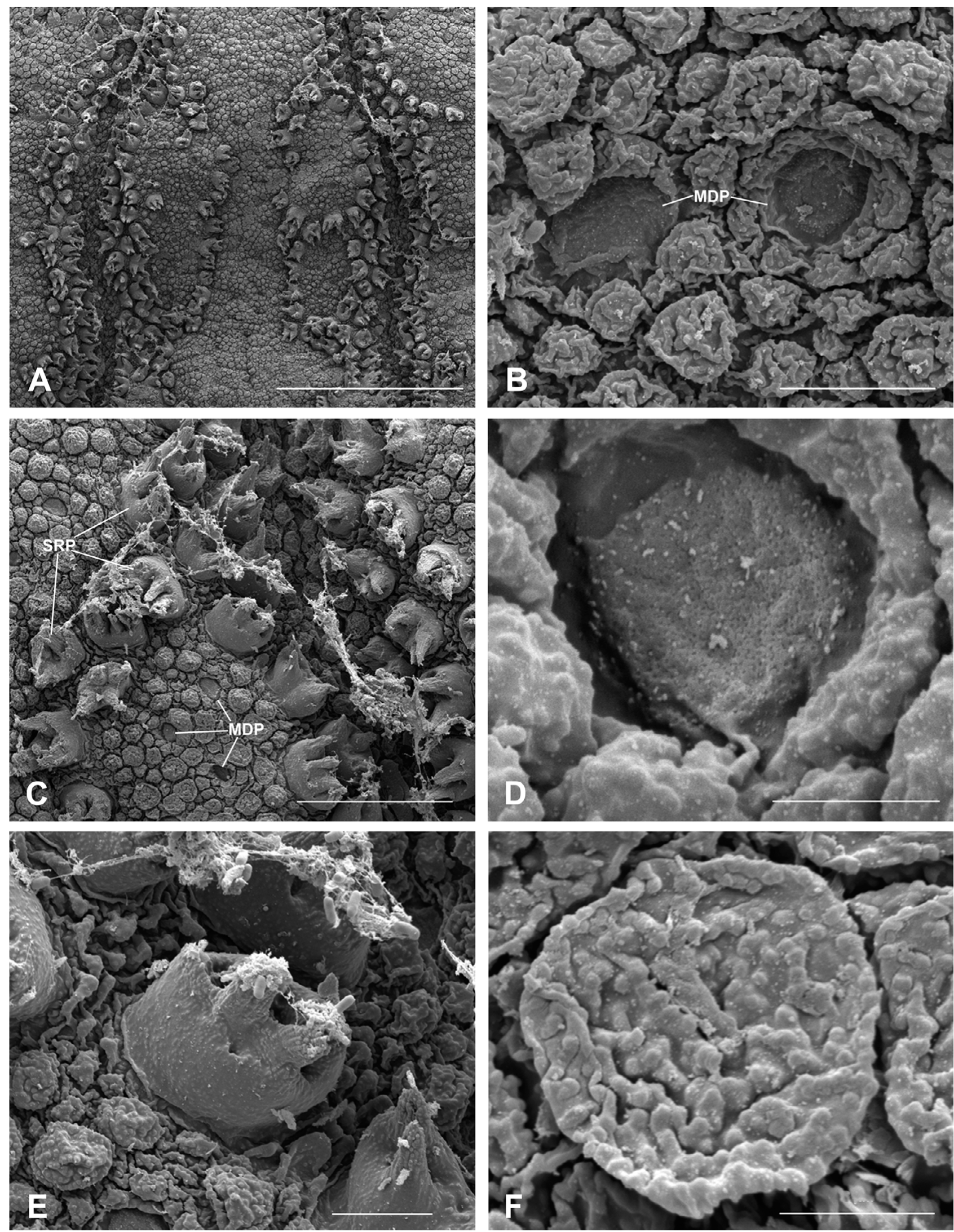

Fig. 9. Details of the dorsum of a second instar larva of Microdon mutabilis: A, C, E-dorsal reticulation: A - anteromedial part; C - detail of the former; $\mathrm{E}$ - single crown-shaped process; B, D, F - dorsal microsculpture: B - wrinkled microscupture; D - detail of multiperforate and depressed plate; $\mathrm{F}$ - detail of the microsculpture. MDP - multiperforate and depressed plate; SRP - simple reticulation process. Scale bars: $\mathrm{A}=200 \mu \mathrm{m} ; \mathrm{B}, \mathrm{E}=10 \mu \mathrm{m} ; \mathrm{C}=50 \mu \mathrm{m} ; \mathrm{D}, \mathrm{F}=3 \mu \mathrm{m}$. 

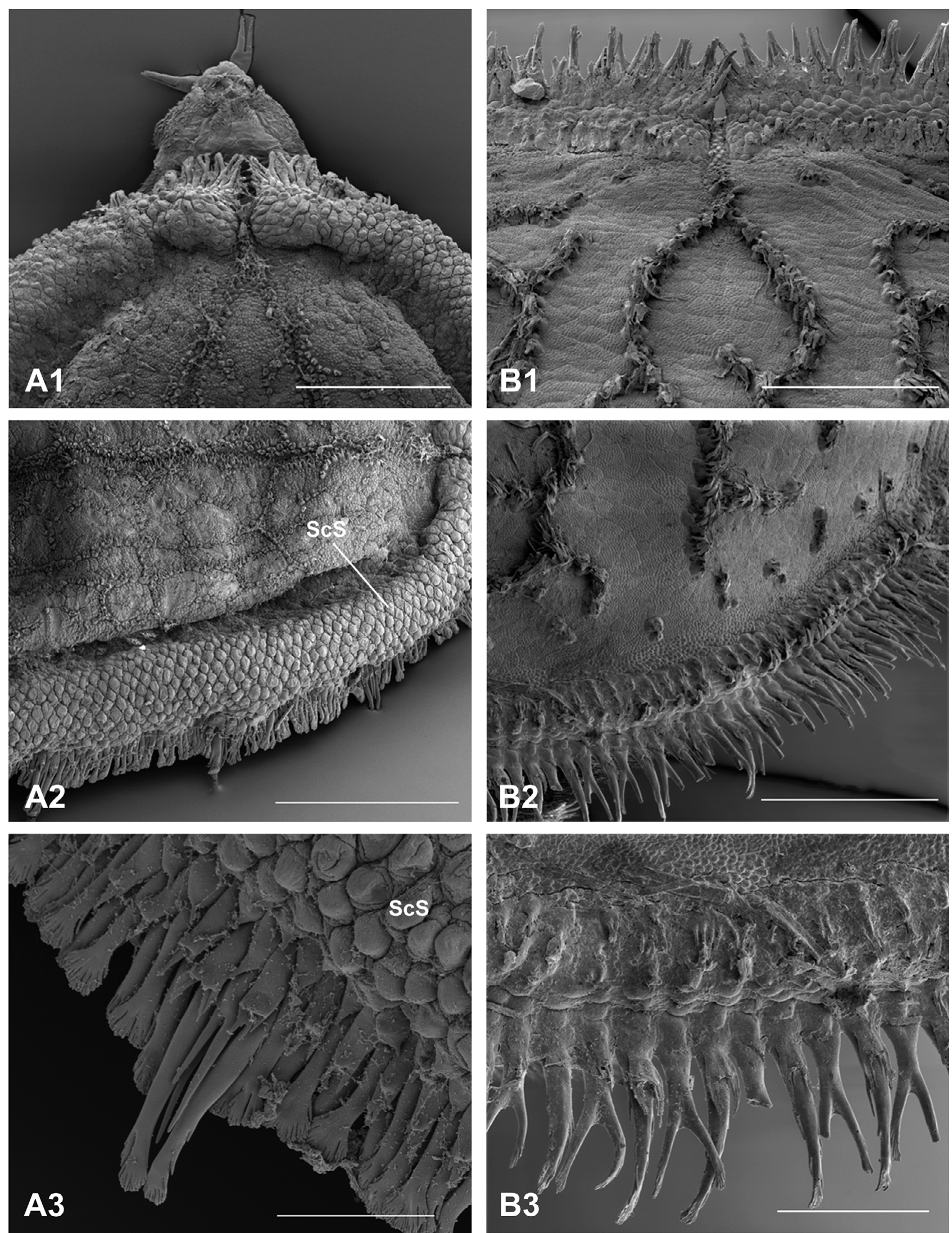

Fig. 10. Marginal bands of second and third instar larvae of Microdon mutabilis: A - second instar larva: A1 - anterior part of marginal band in dorsal view, note the bifurcate marginal band processes; A2 - cuticular frame covered by scallop-like sculpticels; A3 - longer marginal band processes combined with spiniform setae; B - third instar larva: B1, B2, B3 - different views of marginal band processes: single or bifurcate. ScS - scallop-like sculpticels. Scales bars: A1 $=400 \mu \mathrm{m} ; \mathrm{A} 2, \mathrm{~B} 1, \mathrm{~B} 2=500 \mu \mathrm{m} ; \mathrm{A} 3=100 \mu \mathrm{m} ; \mathrm{B} 3=200 \mu \mathrm{m}$. 

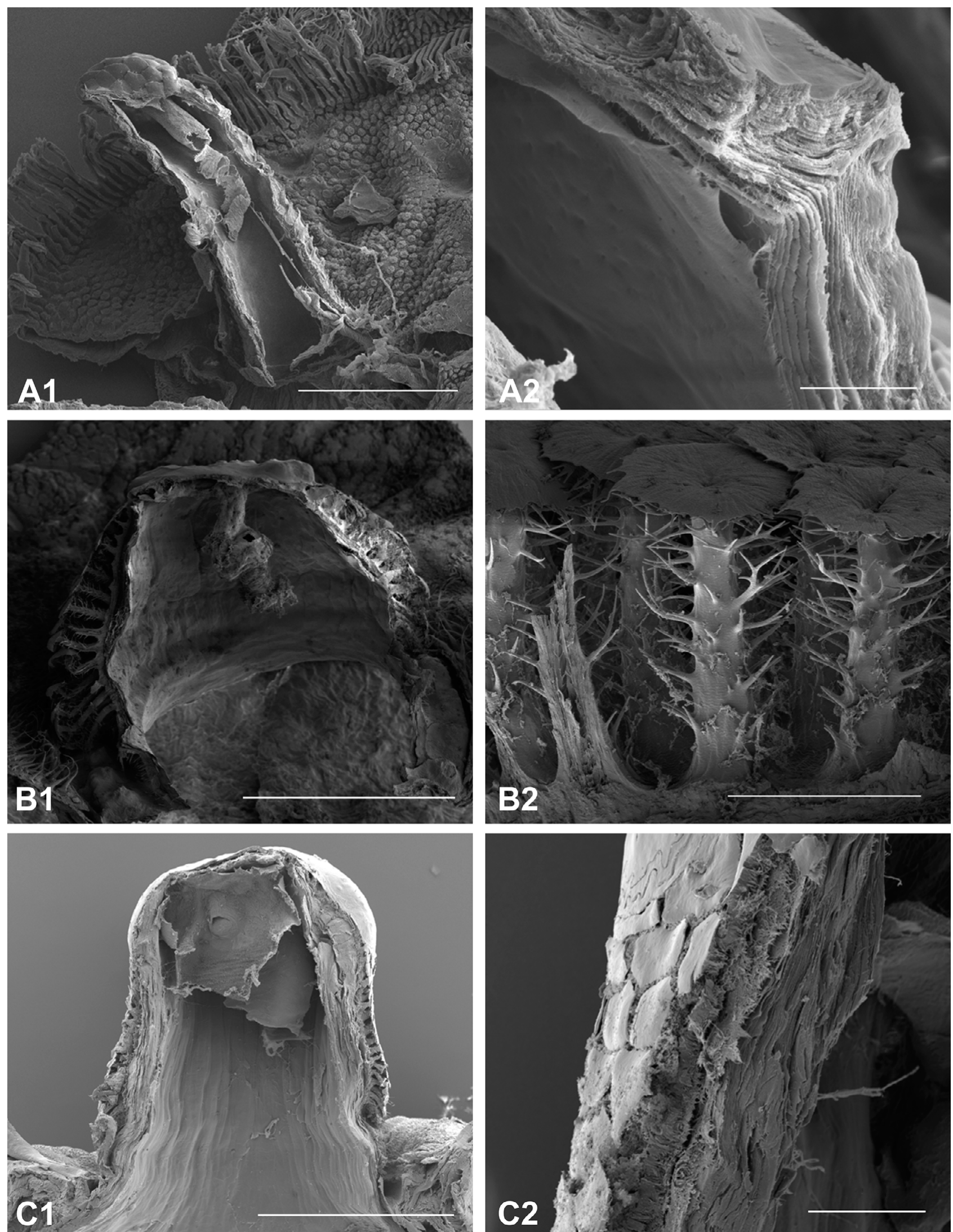

Fig. 11. Sections through the posterior spiracle of Microdon mutabilis: A - first instar larva: A1 - lateral view; A2 - detail of multilayered wall; B - second instar larva: B1 - lateral view; B2 - arborescent structures on the wall; C - third instar larva: C1 - lateral view; C2 - spiracle wall. Scale bars: A1 $=100 \mu \mathrm{m} ; \mathrm{A} 2=5 \mu \mathrm{m} ; \mathrm{B} 1=400 \mu \mathrm{m} ; \mathrm{B} 2, \mathrm{C} 2=50 \mu \mathrm{m} ; \mathrm{C} 1=500 \mu \mathrm{m}$. 
inwardly curved denticles, the posterior bigger and more spiniform than the anterior ones (Fig. 6B2). Processes on the marginal band short, smooth, with cylindrical stem and distal portion with a double, alternate conformation: single or biramous (Figs 10B1-B2-B3). No spiniform setae along marginal band.

Puparium (Figs 12,13) mean body width $=0.74 \mathrm{~mm}, \mathrm{sd}$ $=0.04$; mean body length $=0.92 \mathrm{~mm}, \mathrm{sd}=0.03(\mathrm{n}=10)$

Differs from third instar larva as follows: Entire body surface strongly sclerotized and reddish brown (Figs 13C1-C2). Pseudocephalon retracted, not visible in dorsal view. Two prothoracic dome-shaped spiracles emerging anterodorsally (Fig. 12A). Each anterior spiracle wider than long, smooth at apex, furrowed by about 80 radially disposed respiratory fissures (Figs 12A-C); each fissure on a small papilla (Fig. 12E). Base of prothoracic horns, viewed internally, encircled by a cuticular ring (Fig. 12B).

\section{Locomotion (Supplementary file1)}

Movement is peristaltic (similar to the foot of snails), mainly performed by using the ventral muscular plate, which is covered with hairy microsculpture. The peristalsis can involve the whole body in first instar larvae, which can quite rapidly completely stretch and contract their bodies. Due to the hardening and thickening of the dorsal part of their bodies, movement in second and third instar larvae is slower and only consists of repeated contraction and relaxation of muscles that propagate an anterograde wave, starting in the anal region of the ventral plate. However, first instar larvae can also move slowly. During this movement the larva slides forward the hairy medial part of the ventral plate on a wet, mucous, adhesive layer. This larva can also move backwards and sideways, or just rotate its body by contracting and partially folding its sides, which determines the direction. For the backward and sideward movements the waves of contraction start on the anterior part of the plate and go backwards. The mandibles are not involved in locomotion and remain retracted, while the head, completely protracted during locomotion, is swung from side to side and explores the environment.

\section{Feeding behaviour (Supplementary file 2)}

We observed and filmed a second instar larva of M. mutabilis feeding on pupae and larvae of Formica cunicularia. The feeding behaviour consists of first approaching prey at a 90 degree angle while swinging its pseudocephalon from side to side. When the prey is reached, M. mutabilis partially raises the anterior part of its body and starts a sequence of vigorous and deep lunges into the prey's integument via repeated and complete protractions and retractions of its mouthparts. After lacerating the prey's integument, the $\mathrm{Mi}$ crodon larva starts sucking the body fluids of its prey by means of a pumping action of the pharynx,. The extreme mobility of the head skeleton enables the larva to reach different areas inside the prey.

\section{DISCUSSION}

The study of myrmecophiles is challenging because they are rare, live in concealed environments (ant nests) and the interactions with their hosts are complex (Di Giulio et al., 2011). While it is difficult to study their behaviour and life cycle in nature, it is also difficult to rear them in laboratory. Because of these difficulties that hamper direct observations, the nature of most interactions between myrmecophiles and ants, and the function of many structural adaptations still remain a mystery or a matter of speculation (e.g., Di Giulio \& Moore, 2004). Most myrmecophiles have evolved ways of being accepted by ants and of surviving and developing in their nests. Such adaptations include: chemical and morphological mimicry; specialized feeding behaviour and ways of inducing ants to feed them; and structural and chemical modifications that enable them to avoid being attacked by ants (Thomas et al., 2005; Lachaud et al., 2013). This is also the case for species of Microdon, whose biology has been inferred mostly from occasional observations in the field and laboratory (Garnett et al., 1985; Barr, 1995; Elmes et al., 1999; Wolton, 2011).

The exceptional finding of a large number of second and third instar larvae and pupae (159 specimens, see Table 1) of M. mutabilis inside Formica cunicularia nests in Central Italy, enabled us to rear them and obtain eggs and first instar larvae. By using light, fluorescence and SEM microscopy, we have described in detail and illustrated the external features of all the immature stages of M. mutabilis (eggs, larvae and pupae).

\section{Functional morphology}

The three larval instars strongly differ from each other, in particular in the shape of their body, the posterior spiracular tubercle (Fig. 7) and the cephaloskeleton (Fig. 6). The modifications of these parts during development are probably linked to the different behaviours of the larval instars inside the nest of the host and to specific morpho-functional constraints.

First, a body, which changes from soft and flattened (first instar) to hard (though not sclerotized) and strongly domeshaped (third instar), constrains their locomotion, which in the third instar involves slug-like slipping on a hairy, mucous ventral plate. Since eggs are laid outside the nests of their host, the newly eclosed first instar larvae possibly need to be highly mobile in order to enter a nest and reach the brood of the ant. The slow and bulged third instar larva is, instead, already in the brood chamber, where it develops up to pupal stage, and its strongly convex shape and hard and thick dorsal cuticle are likely to protect them from occasional attacks by ants. Furthermore, it is hypothesized that the presence of parasites inside the nest can stimulate the ants to leave the parental nest and move to another place. The empty nest, successively, can be re-occupied by other species of ants, which are not hosts of Microdon and consequently able to recognize this parasite (Schönrogge et al., 2000). In these rare cases the protective structure of the larvae could help them to resist the attacks of ants, which physically cannot bite and hold the larval body because it is too big, thick and without areas that can be gripped and held by ants.

Second, the function of resilin in the external layer of the posterior spiracular tubercle in first instar larvae is still 

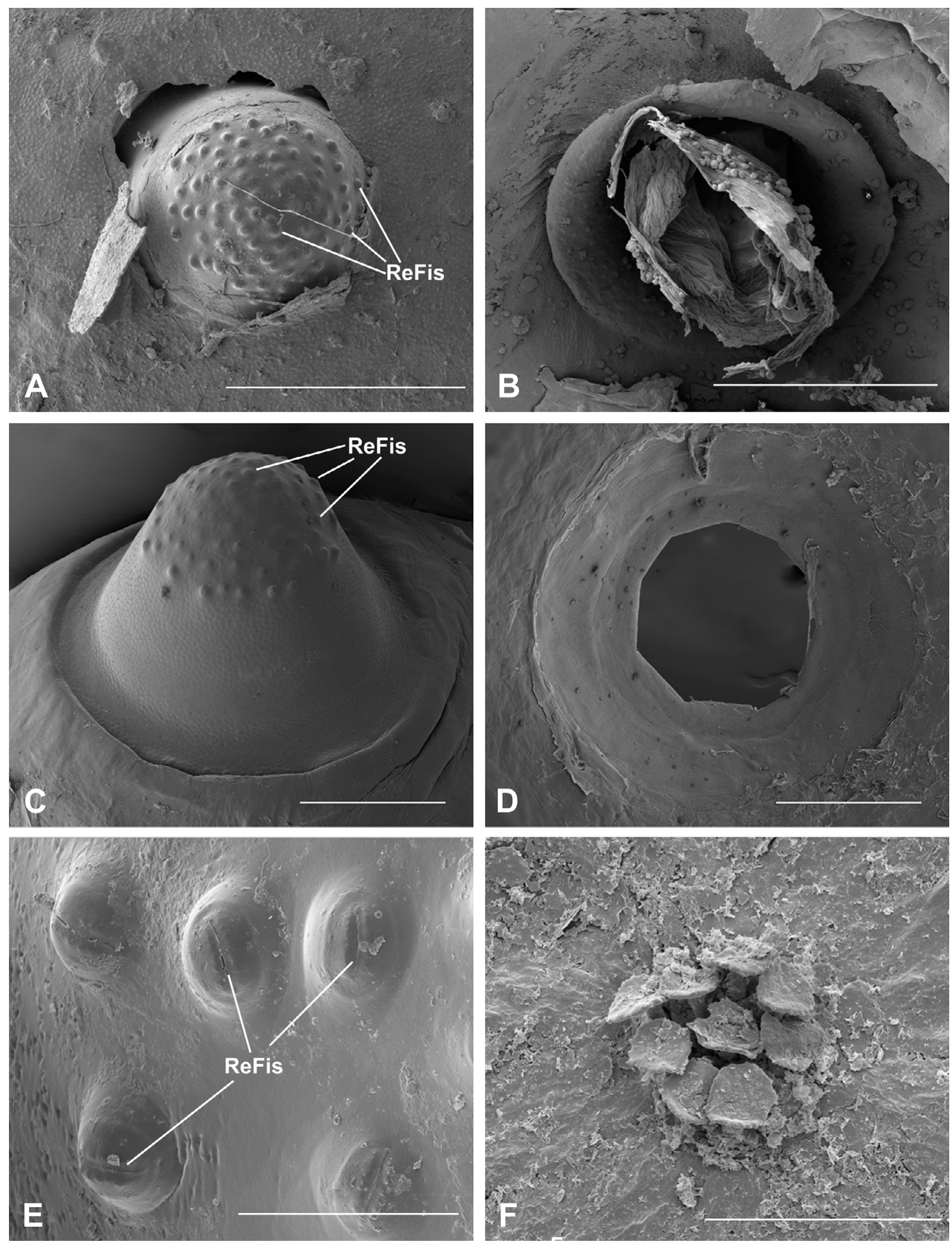

Fig. 12. Third instar larva and puparium of Microdon mutabilis: A-E - prothoracic horn of puparium: A - apical view of the left dome-shaped horn; B - base of prothoracic horn, internal view; C - prothoracic horn extracted from the integument; D - inner side of integument without the prothoracic horn; $\mathrm{E}$ - papillary respiratory fissures; $\mathrm{F}-$ umbrella-like structures on surface of a third instar larva and puparium. ReFis - respiratory fissure. Scale bars: $A, B=500 \mu \mathrm{m} ; C, D=300 \mu \mathrm{m} ; E=50 \mu \mathrm{m} ; \mathrm{F}=100 \mu \mathrm{m}$. 

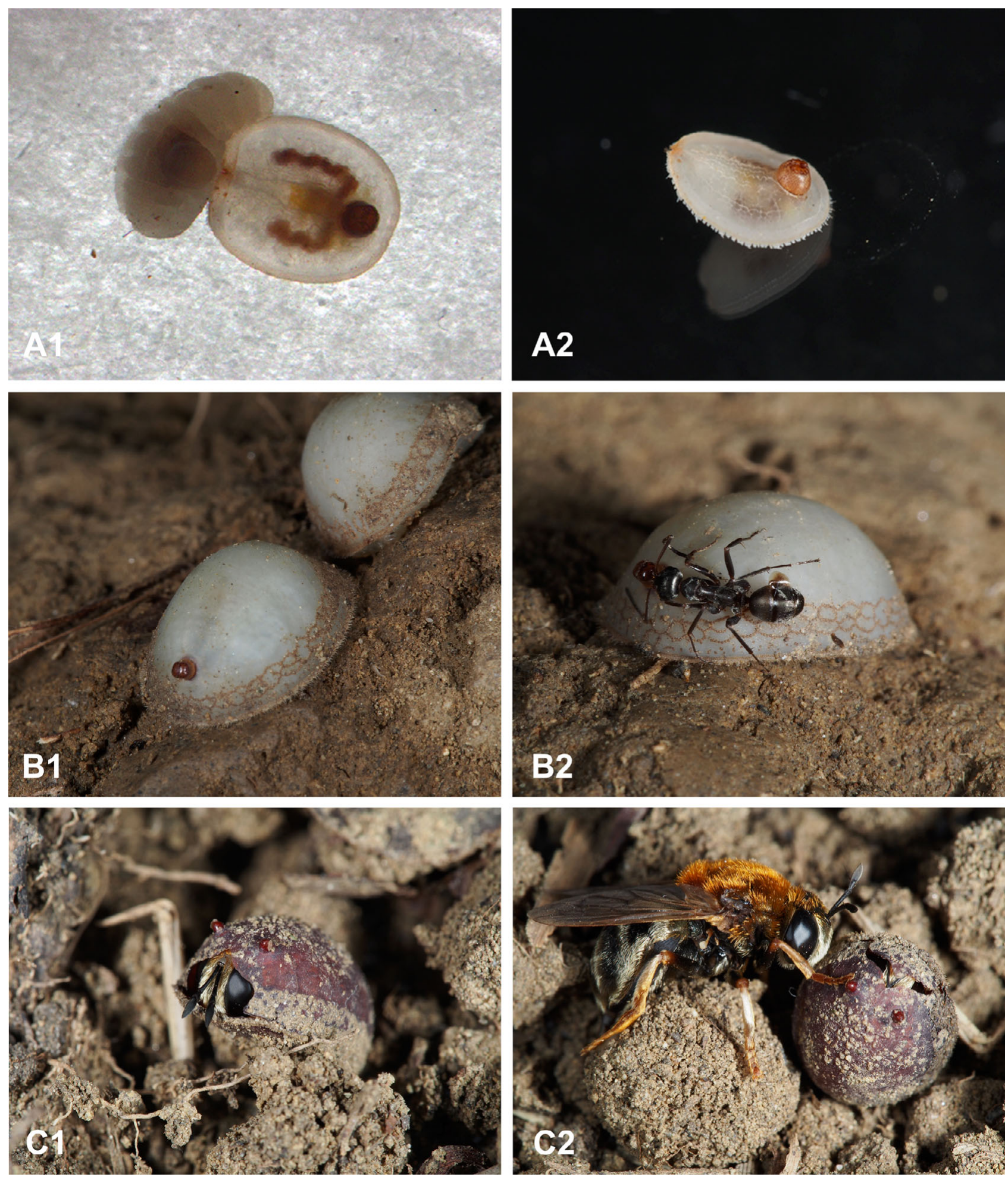

Fig. 13. Photographs of living Microdon mutabilis: A - second instar larva: A1 - feeding on a larva of Formica cunicularia; A2 - dorsolateral view; B - third instar larvae: B1 - two larvae inside ant nest; B2 - larva with a worker of Formica cunicularia; C1 - adult emerging from puparium, anterior view; C2 - adult with pupa.

unclear, but it certainly increases the elasticity of this structure and may be related to its exceptional length (Fig. 7A2) and thus to frequent mechanical stress. It is noteworthy that the short and strongly sclerotized, dome shaped posterior spiracles of second and third instar larvae do not have resilin. We can speculate that the increased flexibility may be related either to possible manipulation by the host's mandi- bles (it is unknown whether the ants actively transport the first instar larvae, but if they do, the long tubercle might be used as a "handle"), or associated with active infiltration of these small larvae into the nest through the soil where such a long "snorkel" could be damaged.

Third, as already stressed, the structure of the cephaloskeleton undergoes great modification during larval devel- 
opment, mostly in terms of the mandibles. In first instar larvae the mandibles are fused and form a unique serrated blade while in second and third instar larvae the mandibles are separated into two blades that are mesodorsally connected.

The SEM analysis revealed the fine morphology of the peculiar flower-like structures present on both the dorsal and ventral surfaces of the bodies of larvae of M. mutabilis. Garnett et al. (1990) describe homologous structures as sensilla in other North American species, and for this reason in this work we refer to those of M. mutabilis as flower-like sensilla. The presence of a pore in the medial dome of these flower-like sensilla could indicate they have a chemoreceptive function, though a possible glandular function cannot be excluded. A glandular function is very likely for the dorsal processes that make up the reticulations typical of most third instar larvae of Microdon, including M. mutabilis in which pores and a sticky substance associated with these processes were recorded in this study. The functional role of these secretions in these predators is still obscure, since we did not see an ant licking the bodies of larvae, as is reported in other myrmecophiles that offer ants appeasing substances.

\section{Results of field sampling and captive breeding}

Although Microdon mutabilis is a relatively rare species, considered endangered in many countries (Schönrogge et al., 2002; Van de Meutter et al., 2009), we found a large number of specimens (72 inside a single ant nest!), if compared with Microdon myrmicae, for which the maximum number of specimens recorded per nest is 27 (Witek et al., 2012). The detection of parasitized nests was, however, difficult, and so far only 4 nests with $M$. mutabilis have been found. The field site in Central Italy is very similar to the one described for M. myrmicae (Gammelmo \& Aarvik, 2007; Van de Meutter et al., 2009; Wolton, 2011).

During our laboratory rearing several Microdon adults were observed entering a nest of Formica cunicularia where they were immediately recognized and attacked by ants. In the literature it is documented that the methyl 6-methylsalicylate, a constituent of the mandibular gland secretion of many Formicidae, could have a role in the recognition of a suitable Formica lemani nest (Schönrogge et al., 2008). It seems plausible that the M. mutabilis we reared could have perceived this or a similar compound and used it to locate the artificial nest of F. cunicularia.

In the laboratory we placed some third instar $M$. mutabilis larvae in an artificial nest with $F$. cunicularia workers and brood from the nest in which these parasitic larvae were found, and noted that all the ant workers aggregated on the dorsal surface of the syrphid larvae in the same way as they aggregate on their brood. Similar behaviour is described by Barr (1995) after having placed 6 M. mutabilis larvae found in a $F$. lemani nest within an artificial nest of Myrmica ruginodis (Nylander, 1846); in this case the author interpreted this as an attempt by ants to prevent the social parasites from feeding on the ant brood. However, alternative hypotheses are also possible and a protective behaviour of the ant workers toward brood seems more likely based on the chemical mimicry reported in the literature for other Microdon species (Howard et al., 1990a, b) and their host ants.

\section{Feeding behaviour}

The hemicryptocephalic condition, with no sclerotization of external parts of the head coupled with a further development of an internal cephaloskeleton that characterizes larvae of the Muscomorpha (= cyclorrhaphous Brachycera) is a derived condition within the order Diptera (Stehr, 1991). A protractile and highly mobile pseudocephalon is advantageous for fly larva, since it can maximize the exploitation of a food resource and, as suggested by Rotheray \& Lyszkowski (2015), is energy-efficient because the rest of the body remains immobile. The mandibles of species of Microdon differ from those of some other Cyclorrapha, because they are enlarged and finely and tightly serrated. This is likely a derived condition, which strongly characterizes Microdon. Most predatory cyclorraphans use hooklike mandibles to perforate the integument of their prey. Phaonia goberti (Mik) and Phaonia subventa (Harris), two predatory species of the family Muscidae, are able to pierce the prey's integument using their mandibles, supported by the parastomal bar, almost as scissors (Rotheray \& Wilkinson, 2015). In M. mutabilis, as in other species of Microdon (Rotheray \& Lyszkowski, 2015), the bladelike mandibles saw through their prey's tissues like a knife. The presence of a medial lobe on the labial sclerite bearing apically small teeth could help to stabilize the mandibles gripping the prey and thus facilitate feeding. After piercing the integument, M. mutabilis starts to suck the body fluids of its prey.

\section{Locomotion}

The absence of thoracic legs strongly affects the mobility of dipteran larvae. Many flies, especially those in brachyceran groups with hook-like mandibles, move their mouthparts vertically and obliquely to hook on to the substrate and establish an anchor point on which they slide the rest of the body (Berrigan \& Pepin, 1995, Schneeberg \& Beutel, 2015), whereas, locomotion in M. mutabilis is performed without using the head skeleton. The highly developed ventral musculature in $M$. mutabilis, coupled with the enlarged body with a flat "foot", is sufficient to allow an autonomous movement without the need of mandibles, in way analogous to slugs with which they were initially confused (Reemer, 2012). Furthermore, the blade-like mandibles of Microdon are not suitable for attaching to the substrate for supporting the larval body during a peristaltic wave. Concerning the marginal band, which encircles the larval body, from the behavioural observations in the laboratory of the different larval instars, it does not seem to be directly involved in locomotion, but its primary role seems to be to perceive mechanical information with the radial setae in order to orientate and freely move inside the galleries. 


\section{Host specificity}

M. mutabilis was presumed to be associated exclusively with the ant species Formica lemani (Elmes et al., 1999; Schönrogge et al., 2002). This was one of the major points that led Schönrogge et al. (2002) to split off specimens associated with Myrmica species, notably M. scabrinodis, as a cryptic new species named Microdon myrmicae. In Central Italy, specimens identified by us as $M$. mutabilis (again the identification was largely based on the association with the ant genus Formica) were found in nests of Formica cunicularia, which is a new host for this species. These new records and some sporadic records of $M$. mutabilis larvae with other species of the genus Formica and some of Lasius (Andries, 1912; Donisthorpe, 1927; Schmid, 2004; Remeer, 2013; Speight, 2013) cast doubt on the "extreme host specificity" theory and the status of $M$. myrmicae may need re-evaluation.

Other species of Microdon are also found with many different species of ants (Howard et al., 1990a; Schmid, 2004; Reemer, 2013). The most striking example is that of $M$. albicomatus, a North American parasite, which has a great variety of host species, almost all of the genus Formica as well as Myrmica incompleta Provancher, 1881 (Howard et al., 1990b) and thus exploits species of two different subfamilies, Formicinae and Myrmicinae. From these records, a wider host specificity of the species of Microdon seems plausible. The hypothesis of "extreme host specificity” (Elmes et al., 1999; Schönrogge et al., 2002, 2006) proposed for some species, could be valid only at a local scale, given their low dispersal ability. However, it cannot be excluded that some of the species of Microdon known to use more than one ant genus could be a complex of species.

In conclusion, we stress the importance of scanning electron microscopy, combined with light microscopy, as an invaluable tool for analysing the external morphology of the immature stages of Microdon, and for drawing inferences about the behavioural ecology of these elusive insects. The fine morphological analysis of all external (i.e., microsculpture, appendages, sensorial organs, spiracles) and internal (i.e., cephaloskeleton) structures is also a potential source of diagnostic characters, especially important in a genus like this where many cryptic species are recognized.

ACKNOWLEDGEMENTS. We thank our colleagues M.A. Bologna, M. Molfini, A. Riccieri and G. Cappelli for their help during the field sampling and M. Muzzi for his support during laboratory work. Electron microscopy analyses were done at L.I.M.E. (Laboratorio Interdipartimentale Microscopia Elettronica) of University of Roma Tre and funded by Department of Science Research Grants (CAL Di Giulio 2017).

\section{REFERENCES}

Akre R.D. \& Paulson G.S. 1993: Who's eating the children? (Most unusual flies). - Am. Entomol. 39: 238-243.

Akre R.D., Alpert G. \& Alpert T. 1973: Life cycle and behaviour of Microdon cothurnatus in Washington (Diptera: Syrphidae). - J. Kans. Entomol. Soc. 46: 327-338.

ANDRIES M. 1912: Zur Systematik, Biologie und Entwicklung von Microdon Meigen. - Z. Wiss. Zool. (Abt. A) 103: 300-361.
BARR B. 1995: Feeding behaviour and mouthpart structure of larvae of Microdon eggeri and Microdon mutabilis (Diptera, Syrphidae). — Dipt. Digest 2: 31-36.

Berrigan D. \& Pepin D.J. 1995: How maggots move: Allometry and kinematics of crawling in larval Diptera. - J. Insect Physiol. 41: 329-337.

Brown V.B., Hash J.M., Hartop E.A., Porras W. \& Amorim D.S. 2017: Baby killers: Documentation and evolution of scuttle fly (Diptera: Phoridae) parasitism of ant (Hymenoptera: Formicidae) brood. - Biodivers. Data J. 5: e11277, 9 pp.

Courtney G.W., Sinclair B.J. \& Meier R. 2000: Morphology and terminology of Diptera larvae. In Papp L. \& Darvas B. (eds): Contributions to a Manual of Palaearctic Diptera. Vol. 1. Science Herald, Budapest, pp. 85-161.

Di Givlio A. \& Moore W. 2004: The first-instar larva of the genus Arthropterus (Coleoptera: Carabidae: Paussinae): implications for evolution of myrmecophily and phylogenetic relationships within the subfamily. - Invertebr. Syst. 18: 101-115.

Di Giulio A., Maurizi E., Hlavác P. \& Moore W. 2011: The longawaited first instar larva of Paussus favieri (Coleoptera: Carabidae: Paussini). - Eur. J. Entomol. 108: 127-138.

Doczkal D. \& Schmid U. 1999: Revision der mitteleiropäischen Arten der Gattung Microdon Meigen (Diptera, Syrphidae). Volucella 4: 45-68.

Donisthorpe H.J.K. 1927: The Guests of British Ants - Their Habits and Life-Histories. George Routledge, London, 244 pp.

Elmes G.W., Barr B., Thomas J.A. \& Clarke R.T. 1999: Extreme host specificity by Microdon mutabilis (Diptera: Syrphidae), a social parasite of ants. - Proc. R. Soc. Lond. (B) 266: 447-453.

Evenhuis N.L., Sarnat E. \& Tokota'A M. 2007: New genus and species of sciarid ant guest from Fiji (Diptera: Sciaridae) with an annotated checklist of Fiji sciarids. In Evenhuis N.L. \& Bickel D.J. (eds): Fiji Arthropods IX. - Bishop Mus. Occas. Papers 94: 3-10.

Gammelmo Ø. \& Aarvik L. 2007: The myrmecophilous fly Microdon myrmicae Schönrogge et al., 2002 (Diptera, Syrphidae) in Norway. - Nor. J. Entomol. 54: 43-48.

Garnett W.B., Akre R.D. \& Sehlke G. 1985: Cocoon mimicry and predation of myrmecophilous Diptera (Diptera: Syrphidae). - Fla Entomol. 68: 615-621.

Garnett W.B., AKRe R.D. \& ZACK R.S. 1990: External morphology of four species of Microdon immatures (Diptera: Syrphidae) from the Pacific Northwest. - Ann. Entomol. Soc. Am. 83: $68-80$.

Gösswald K. 1950: Pflege des Ameisenparasiten Tamiclea globula Meig. (Dipt.) durch den Wirt mit Bemerkungen über den Stoffwechsel in der parasitierten Ameise. - Verh. Dtsch. Zool. Ges. 1949: 256-264.

Hölldobler B. \& Wilson E.O. 1990: The Ants. Springer, Berlin, $739 \mathrm{pp}$.

Howard R.W., Akre R.D. \& Garnett W.B. 1990a: Chemical mimicry in an obligate predator of carpenter ants (Hymenoptera: Formicidae). - Ann. Entomol. Soc. Am. 83: 607-616.

Howard R.W., Stanley-Samuelson D.W. \& Akre R.D. 1990b: Biosynthesis and chemical mimicry of cuticular hydrocarbons from the obligate predator, Microdon albicomatus Novak (Diptera: Syrphidae) and its ant prey, Myrmica incompleta Provancher (Hymenoptera: Formicidae). - J. Kans. Entomol. Soc. 63: 437-443.

Ivens A.B.F., von Beeren C., Bluthgen N. \& Kronauer D.J.C. 2016: Studying the complex communities of ants and their symbionts using ecological network analysis. - Annu. Rev. Entomol. 61: 353-371.

Kistner D.H. 1982: Social insects bestiary. In Hermann H.R. (ed.): Social Insects. Academic Press, New York, 244 pp. 
LACHAud J.-P. \& PÉREZ-Lachaud G. 2015: Ectaheteromorph ants also host highly diverse parasitic communities: a review of parasitoids of the Neotropical genus Ectatomma. - Insectes Soc. 62: 121-132.

Lachaud J.-P., Alain Lenoir A. \& Hughes D.P. 2013: Ants and their parasites. - Psyche 2013: 264279, 5 pp.

Lachaud J.-P., Klompen H. \& Pérez-Lachaud G. 2016: Macrodinychus mites as parasitoids of invasive ants: an overlooked parasitic association. - Sci. Rep. 6: 29995, 10 pp.

Pape T., Beuk P., Pont A.C., Shatalkin A.I., Ozerov A.L., Woźnica A.J., Merz B., Bystrowski C., Raper C., Bergström C. ET AL. 2015: Fauna Europaea: Diptera - Brachycera. - Biodiv. Data J. 3: e4187, 31 pp.

Parker J. \& GRimaldi D.A. 2014: Specialized myrmecophily at the ecological dawn of modern ants. - Curr. Biol. 24: 24282434.

Pereira T.P.L., Bravo F., Araújo M.X., Cordeiro D., Chagas C. \& Delabie J.H.C. 2015: Moth flies (Diptera: Psychodidae) collected in colonies of the fire ant Solenopsis virulens (Smith) (Hymenoptera: Formicidae), with description of two new species. - Sociobiology 62: 18-22.

Pérez-Lachaud G., Jervis M.A., Reemer M. \& Lachaud J.-P. 2014: An unusual, but not unexpected, evolutionary step taken by syrphid flies: the first record of true primary parasitoidism of ants by Microdontinae. - Biol. J. Linn. Soc. 111: 462-472.

Pérez-Lachaud G., Jahyny B.J.B., Ståhls G., Rotheray G., DeLABIE J.H.C. \& LACHAUd J.-P. 2017: Rediscovery and reclassification of the dipteran taxon Nothomicrodon Wheeler, an exclusive endoparasitoid of gyne ant larvae. - Sci. Rep. 7: $45530,9 \mathrm{pp}$.

ReEmer M. 2012: Unravelling a Hotchpotch. Phylogeny and Classification of the Microdontinae (Diptera: Syrphidae). $\mathrm{PhD}$ thesis, Leiden University, $384 \mathrm{pp}$.

ReEMER M. 2013: Review and phylogenetic evaluation of associations between Microdontinae (Diptera: Syrphidae) and ants (Hymenoptera: Formicidae). — Psyche 2013: 538316, 9 pp.

RothERAY G.E. 1991: Larval stages of 17 rare and poorly known British hoverflies (Diptera: Syrphidae). - J. Nat. Hist. 25: 945-969.

RothERAY G.E. \& LYSZKOWSKI R.L. 2015: Diverse mechanisms of feeding and movement in cyclorrhaphan larvae (Diptera). $-J$. Nat. Hist. 50: 2139-2211.

Rotheray G.E. \& WiLKINSON G. 2015: Trophic structure and function in the larva of predatory muscid flies (Diptera, Muscidae). - Zoomorphology 134: 553-563.

Schmid U. 2004: Microdon rhenanus and Microdon eggeri var. major (Diptera, Syrphidae) revisited. — Volucella 7: 111-124.

Schneeberg K. \& Beutel R.G. 2015: The evolution of head structures in lower Diptera. Ver. 2. - ScienceOpen Res. 2015, 28 pp. DOI: 10.14293/S2199-1006.1.SOR-LIFE.ALTCE1.v2.

Schönrogge K., Wardlaw J.C., Thomas J.A. \& Thomas G.W. 2000: Polymorphic growth rates in myrmecophilous insects. - Proc. R. Soc. Lond. (B) 267: 771-777.

Schönrogge K., Barr B., Wardlaw J.C., Napper E., Gardner M.G., Breen J., Elmes G.W. \& Thomas J.A. 2002: When rare species become endangered: cryptic speciation in myrmecophilous hoverflies. - Biol. J. Linn. Soc. 75: 291-300.

Schönrogge K., Gardner M.G., Elmes G.W., NapPer E.K.V., Simcox D.J., Wardlaw J.C., Breen J., Barr B., Knapp J.J., Pickett J.A. \& Thomas J.A. 2006: Host propagation permits extreme local adaptation in a social parasite of ants. - Ecology Lett. 9: 1032-1040.
Schönrogge K., Napper E.K.V., Birkett M.A., Woodcock C.M \& Thomas J.A. 2008: Host recognition by specialist hoverfly Microdon mutabilis, a social parasite of the ant Formica lemani. - J. Chem. Ecol. 34: 168-178.

SpeIGHT M.C.D. 2004: Fauna Europaea: Syrphidae. In Pape T. (ed.): Fauna Europaea: Diptera, Brachycera. Ver. 1.1. URL: http://www.faunaeur.org.

Speight M.C.D. 2008: Database of Irish Syrphidae (Diptera). Irish Wildlife Manuals No. 36. National Park and Wildlife Service, Department of Environment, Heritage and Local Government, Dublin, 344 pp.

Speight M.C.D. 2013: Species accounts of European Syrphidae (Diptera). In Speight M.C.D., Castella E., Sarthou J.-P. \& Monteil C. (eds): Syrph the Net, the Database of European Syrphidae. Vol. 72. Syrph the Net Publications, Dublin, 316 pp.

Speight M.C.D. \& SARthou J.-P. 2011: StN keys for the identification of adult European Syrphidae (Diptera), Glasgow 2011. In Speight M.C.D., Castella E., Sarthou J.-P. \& Monteil C. (eds): Syrph the Net, the Database of European Syrphidae. Vol. 66. Syrph the Net Publications, Dublin, $120 \mathrm{pp}$.

STHER F.W. 1991: Immature Insects. Vol. 2. Kendall/Hunt, Iowa, $930 \mathrm{pp}$.

Thomas J.A., Schönrogge K. \& Elmes G.W. 2005: Specializations and host associations of social parasites of ants. In Fellowes M.D.E., Holloway G.J. \& Rolff J. (eds): Insect Evolutionary Ecology. CABI, Wallingford, pp. 479-518.

Van de Meutter F., Dekoninck W., Mortelmans J., Vantieghem P. \& WAKKIE B. 2009: First confirmed records of Microdon mutabilis and Microdon myrmicae (Diptera: Syrphidae) for Belgium. - Bull. S.R.B.E./K.B.V.E. 145: 116-120.

WHEELER W.M. 1908: Studies on myrmecophiles. III. Microdon. — J. N. Y. Entomol. Soc. 16: 202-213.

WHEELER W.M. 1924: Two extraordinary larval myrmecophiles from Panama. - Zoology 10: 237-244.

WheELER W.M. 1928: The Social Insects: Their Origin and Evolution. Kegan Paul, Treanch, Trubner and Co., London, xviii $+378 \mathrm{pp}$.

Witek M., Canterino S., Balletto E. \& Bonelli S. 2012: Life cycle and growth pattern of the endangered myrmecophilous Microdon myrmicae (Diptera: Syrphidae). - Eur. J. Entomol. 109: 457-461.

Witek M., Patricelli D., Casacci L.P., Barbero F., Balletto E. \& Bonelli S. 2011: Notes on the biology and host ant specificity of the myrmecophilous syrphid fly Microdon major (Diptera: Syrphidae), a social parasite of Formica ants (Hymenoptera: Formicidae). - Sociobiology 57: 261-269.

Wolton R. 2011: Observations on ecology and behaviour of Microdon myrmicae Schönrogge et al. (Diptera, Syrphidae), with a description of egg and early instar morphology. - Dipt. Digest 18: 55-67.

Received August 2, 2017; revised and accepted November 11, 2017 Published online December 15, 2017

\section{Supplementary files:}

Supplementary file 1 (http://www.eje.cz/2017/071/S01.mp4). Locomotion of third instar larvae of Microdon mutabilis. Movements in the ventral surface observed through the transparent bottom of a Petri dish.

Supplementary file 2 (http://www.eje.cz/2017/071/S02.mov). Second instar larva of Microdon mutabilis feeding on a larva of Formica cunicularia. 